\title{
A quick indicator of effectiveness of "capacity building" initiatives of NGOs and international organizations
}

\section{David Lempert}

\begin{abstract}
The article offers an easy-to-use indicator for scholars and practitioners to measure whether NGOs, international organizations, and government policies and projects meet the criteria for design and implementation of "capacity building" projects that have been established by various international organizations and that are recognized by experts in the field. The indicator can be used directly to address failures that are routinely reported in this key and growing development intervention. Use of this indicator on more than a dozen standard interventions funded today by international development banks, UN organizations, country donors, and non-governmental organizations (NGOs) reveals that while many smaller organizations are working to change institutions and society in ways that effectively build long-term capacity, most of the major actors in the field of development have failed to follow their own guidelines. Many appear to be using "capacity building" as a cover for lobbying foreign governments to promote international agendas ("purchasing foreign officials") and/or to increase the power of particular officials at the expense of democracy, with the public lacking simple accountability tools. The indicator points to specific areas for holding development actors accountable in order to promote development goals of sustainability and good governance. The breadth of the field of "capacity building" also allows this indicator to be used, with some modifications, for a large variety of development interventions. This article also offers several examples of where current capacity building projects fail, along with a sample test of the indicator using UNCDF as a case study.
\end{abstract}

\section{JEL classification}

D02; P48; L31; O17.

\section{Keywords}

Capacity building; institution building; governance; civil society; development policy. 


\section{Introduction}

"Capacity building" has become the tool of choice for several major international "development" organizations in recent years, including the United Nations system, the World Bank and other development banks, major international government bilateral donors as well as non-governmental organizations. As of 2009 , some $\$ 20$ billion per year of international development intervention funding went for capacity development; roughly 20 percent of total funding in this category (Otoo, Agapitova and Behrens, 2009). The World Bank itself commits more than $\$ 1$ billion per year to this service in loans or grants (more than 10 percent of its portfolio of nearly $\$ 10$ billion) (World Bank, 2005) and identifies it in all of its formulaic country studies as a 'core objective,' while the U.N. system practically defines itself by capacity development as the "how" for "how" UNDP works' to fulfill its mission" ${ }^{32}$. Between 1995 and 2004, the World Bank committed \$9 billion in loans and \$900 million in grants to capacity building; roughly $\$ 1$ Billion per year. In 2007 , the total bank lending was $\$ 9.1$ billion (World Bank, 2005:9). According to recent statistics from the Organization of Economic Cooperation and Development, 12 percent of the $\$ 15$ billion that went to 38 'fragile states' in 2007, of a total official development assistance of $\$ 101.3$ billion, went for 'governance and civil society,' the key area of 'capacity building.' (OECD, 2008:12). Using the OECD figure of $\$ 101.3$ billion, the $\$ 20$ billion reported by Otoo et al (2009) would amount to 20 percent.) According to the UNDP's current promotional campaign, 'capacity is development' and 'the urgency of "how"' (whatever that means) (UNDP Global Capacity Development Facility, 2014) $)^{33}$.

Despite the enormous reliance on this tool to implement missions of (sustainable) 'human development' or the rather different goals of 'poverty reduction; economic growth; improved services' (World Bank, 2005) or 'poverty eradication' (UNDP, 2002), the very organizations that are most committed to this tool are also the first to admit that they do not follow their own guidelines (if any) and that results are often the opposite of what they claim they are trying to achieve.

A World Bank review noted that 'examples abound' in which these initiatives 'severely undermine public management in recipient countries and unwittingly block rather than promote progress in public sector reform and institution-building' (World Bank, 2000). Despite such harsh criticisms dating back almost two decades, little has changed since a 2005 study that showed that the World Bank had almost no interest in applying the lessons and clear standards that already existed in the Bank for running such projects; knowingly creating a double standard for its capacity building of foreign governments. 'The Bank does not apply the same rigorous business practices to its capacity building work that it applies in other areas. Its tools-notably technical assistance and training-are not effectively used... Moreover, most activities lack standard quality assurance processes at the design stage, and they are not routinely tracked, monitored, and evaluated' (World Bank, 2005).

A UNDP study of its capacity building projects in 2002 reported almost exactly the same phenomenon and the UNDP has also done little or nothing to correct this problem since. Among the implementing practitioners, 'There were no generally agreed standards as to what should be expected of newly created or strengthened

\footnotetext{
${ }^{32}$ UNDP Website (2014) URL (consulted 17 June 2015): http://www.undp.org/capacity/.

${ }_{33}$ UNDP (2014) Going for Scale, Going for Sustainability, Going for Quality. URL (consulted 17 June 2015): http://www.undp.org/capacity
} 
national capacity or of institution or organisation building (UNDP, $2002^{34}$ ).' Despite the fact that the U.N. system and other reports describe exactly how results based measurements could be done in this field (UNDP $1998^{35}, 2004^{36}, 2006^{37}$ ), with guidelines easily accessible on the Internet, U.N. officials continue to offer the excuse that results 'cannot be easily measured' to justify why they do not follow measurement procedures and apply a double standard. As a practitioner in the field for more than 30 years, it is this author's view that the situation has actually gotten worse rather than better. While others may disagree, there is little that they can point to in terms of oversight or measurements that create accountability in this field. The failures may be by design.

According to one early observer looking at the state of the field, 'capacity building' is simply being used as a 'buzz word' by international agencies for whatever they wish to do, with or without any accountability or logic (Enemark, 2003). The current state of the field among the major donors is such that it appears to have already reached a theatre of the absurd. Projects (some described below) may be the equivalent of seeking to turn current government clerks into brain surgeons (or the equivalent of teaching elephants to fly rather than buying birds) in a purported attempt to meet the need for specialized professionals without having to add or fire staff or to establish performance standards. Other projects take the approach of seeking to convince wolves to turn vegetarian through "consciousness-raising" in "rights" or in "learning" how not to be corrupt, rather than facing the real underlying cause of the problem, such as the needs to build walls around the henhouse or find ways to put more power on the side of the hens. Many projects have no measures of intended results and lack fit with a development strategy or logic.

Educators and consultants who work in the field and are paid handsomely to "build capacity" also have little incentive to hold themselves to systematic standards since it might make their contributions obsolete. By definition, the more services they are hired to provide, the more "capacity" they build and the more they profit, whether or not their contribution is really the most efficient, effective or sustainable, or addresses the institutional root causes of the lack of capacity in the first place. Generally, these projects are evaluated with 'smile sheets', asking beneficiaries if they are 'happy' or 'better off' and measuring things like 'raised awareness', 'enhanced skills', and 'improved teamwork' that are 'locally driven', rather than on whether the underlying problems are solved, and refraining from asking whether there may be hidden agendas to buy influence, subsidize elites, and continue dependency (Otoo et al, 2009).

The major donors, themselves, admit that they have little incentive to end the double standard and achieve consistency in this area, despite the fact that they have long ago elaborated clear and basic frameworks and standards for how to appropriately measure key components of capacity building (including strategic planning for efficiency, service delivery, or application of skills). The World Bank's 2005 evaluation noted that practitioners shaped and reshaped definitions and

\footnotetext{
${ }^{34}$ UNDP (2002) Capacity Building for Poverty Eradication: Analysis of and Lessons From Evaluations of UN System Support to Countries' Efforts. URL (consulted 17 June 2015): http://www.un.org/esa/coordination/Capacity_Building_for_Poverty_Eradication.pdf.

35 UNDP (1998) Capacity Assessment and Development. In a Systems and Strategic Management Context. Technical Advisory Paper No.3, Bureau for Development Policy (Bahman Kia and Richard Flaman). URL (consulted 17 June 2015): http://portals.wi.wur.nl/files/docs/ppme/capsystech3-98e.pdf

${ }^{36}$ UNDP (2004) National Human Development Reports (NHDR) and the Use of Governance Indicators. URL (consulted 17 June 2015): http://www.undp.org/oslocentre/docs06/NHDR.pdf.

37 UNDP (2006) A Review of Selected Capacity Development Methodologies, Bureau of Development Policy. URL (consulted 17 June 2015): http://74.125.153.132/search?q=cache:IL3zLvOiv0gJ:www.lacworkspace.undp.org.co/fileadmin/desarrollo_capacidades/Documentos/Resource_CatalogueReview_of_Selected_Capacity_Assessment_Methodologies.doc+UNDP+(1998):+Capacity+Assessmen $\mathrm{t}+\mathrm{and}+\overline{\mathrm{Deve}}$ - opment. + Technical+Advisory+Paper+No.3\&cd=3\&hl=en\&ct=clnk .
} 
standards to suit themselves with some development agencies using 'a narrow definition focused on strengthening organizations and skills', with the World Bank, itself offering 'no operational policy to guide its capacity building works' (World Bank, 2005). A UNDP study in 2002 similarly reported that there was 'no systemwide framework' and that participants' use of the terms 'capacity,' 'capacity building' and 'performance' showed 'wide disparities' (UNDP, 2002). Moreover, almost none of the units within UNDP sought to collect any baseline data and their documents from the two previous decades where such data might exist, routinely "disappeared" into "storage."

The abuse of the "tool" of "capacity building" or the substitution of this tool and its inputs for any measurable development outputs is not unique to this international development intervention (Schachter, 2000). In the absence of clear public pressures and accountability measures, many development actors of good or dubious intent justify interventions on the basis of the importance of the symptoms they are treating rather than on actual measurable impact that they say is too difficult or costly to determine; throwing money to build capacity and "strengthen" whomever receives it, rather than addressing problem causes. They often use their location overseas and their direct relations with foreign officials as ways to further hide their activities from public scrutiny in either the donor or recipient countries. In the area of "capacity building," where the "poor" and members of the "public" are easy to exclude, the transfers of money and resources are often directly from government officials in one (powerful) country to those in another (weaker) country in what can be labelled building the "capacity" of the weaker bureaucrats through a legitimized form of corruption and abuse that circumvents international law. The (perhaps intended) result is that development projects often serve the interests of those government bureaucrats channelling the funds and those who receive them rather than the public that is supposed to benefit from measurable results (Lempert, 2008).

Although some may view statements like this as rather bold, officials in developed countries are often the first to admit that they use 'aid' as a form of 'soft power' (as opposed to military power and economic pressure) in order to manipulate the political systems of weaker countries (Nye, 2004). Moreover, this attempt to influence decisions by government officials in weaker countries through use of financial benefits directed to those officials, in ways that favour the interests of the businesses and peoples of the donor country over other countries and/or over the peoples of the recipient countries, easily meets the definitions of corruption that are recognized under international law and that are the very practices that governments all claim they are trying to eliminate. It would be relatively easy for lawyers to find government officials in both the donor and recipient countries in violation of various provisions of the United Nations Declaration Against Corruption $^{38}$ under Articles 15 and 16 (bribery), 18 (trading influence), and 19 (abuse of functions). Transparency International, the international NGO that is the recognized expert on corruption and that is largely funded by major donor countries, would also classify these behaviours as corruption under their definition of 'political corruption' in which funds are used to influence politicians to 'steer away from good government' and to make decisions on the basis of factors other than the 'public interest' in ways that 'divert resources'. ${ }^{39}$

In answer to these challenges in the development field, recent articles by this author have chosen not merely to expose the problems and call for "change" but

38 U.N. Declaration against Corruption and Bribery in International Commercial Transactions (1996): A/RES/51/191. URL (consulted 17 June 2015): http://www.un.org/documents/ga/res/51/a51r191.htm.

${ }^{39}$ Transparency International (2015). URL
http://www.transparency.org/whatwedo.


have taken some of the initial steps to establish indicators and benchmarks through which the public and organizations can easily arm themselves to hold international development actors accountable to international law, to their mission statements for their interventions and to professional standards. These indicators are offered as easy-to-use tools (essentially, new public "weapons") to create accountability and transparency in the use of public funds in development interventions; directly exposing abuses and offering specific directives for improvements. Previous indicators began with tests of whether development projects met international treaty standards for promoting the agreed development objectives of 'sustainable development' (Lempert and Nguyen, 2008) as well as other basic governance objectives to promote self reliance and end colonial 'dependency' (Lempert, 2009), to build "democracy" and protect rights as key international legal goals of good governance (Lempert, 2010a; 2011) and to hold development professionals to ethics standards in order to eliminate conflicts of interest (Lempert, 1997). This is also part of a larger initiative to build organizations that will monitor and challenge donors (Lempert, 2008).

The article offers an easy-to-use indicator for scholars and practitioners to measure whether NGOs, international organizations, and government policies and projects meet the criteria for design and implementation of "capacity building" in ways that have been established by various international organizations, themselves, and that are recognized by experts in the field. This article also serves as a model for accountability in the use of other developments inputs by offering an approach can be adapted to specific interventions. Indeed, "capacity building" itself is an umbrella for many specific tools - education, awareness, providing equipment, strategic planning, consulting advice, etc. - that can be measured using similar approaches.

The article begins by defining "capacity building" according to basic internationally agreed principles that can be placed into an indicator, then surveys existing indicators, explains why several international "capacity building" projects now fail in the absence of an indicator or standard to hold them accountable to minimal levels of competence, then offers a new indicator and tests it on several categories of projects, including a detailed examination of how to use the indicator on an organization like the United Nations Capital Development Fund ${ }^{40}$ that claims to be doing capacity building as it central tool.

\section{Principles of "capacity building"}

The principles of "capacity building" as a standard development intervention are generally agreed upon not only by major donors but also by the community of nongovernmental organizations and by business consulting firms that do capacity building in the government, private business, and NGO sectors (UNDP, 1991 ${ }^{41}$; 1998; World Bank, 2002; 2004; 2005). This makes it relatively simple to test whether organizations are actually doing what they say they have committed to do.

Though organizations use different wording and order, and much of the wording is confusing given jargon in the field, there are really five key concepts that are the essential basis of capacity building: three of them relating to the ability of a system to operate and perform a public function at three different levels (its legal and political authority or "enabling environment" within a larger social and political context; its managerial ability internally to perform effectively and efficiently that is often referred to as its "institutional development"; and the skills of its staff - its

\footnotetext{
${ }^{40}$ United Nations Capital Development Fund (UNCDF) (2009) Website "About UNCDF". URL (consulted 17 June 2015): http://www.uncdf.org/english/about_uncdf/index.php.

${ }^{41}$ UNDP (1991) A Strategy for Water Sector Capacity Building' in Delft, The Netherlands. URL (consulted 17 June 2015): http://www.gdrc.org/uem/capacity-define.html
} 
"human resources"), one relating to good governance (its public accountability), and one relating to the long term sustainability of the function.

Given that these are generally recognized, they do not need to be detailed here in full, but it is easy to understand the logic of the five elements. To be effective, an organization must have sufficient freedom from constraints to conduct its activities and must be able to use the resources that it has. It also must have people who are skilled, properly selected, compensated and tasked. For public organizations, there must be public oversight of the legal framework, of the organization itself, and of the skills areas (professional and technical fields and the training) and workers applying them to assure they are in line with public needs. This whole system must be sustainable and integrated, not simply driven by donors deciding to toss in resources or training to a specific institution, but working effectively over the longterm with people seeking training according to public needs, being appropriately selected and trained, then selected on merit systems, appropriately compensated and tasked.

Assuming a quick fix of channelling funds or training courses to workers in an institution who may be the wrong people being wrongly tasked or overseen in ineffective organizations, or to educational institutions that may be training people who will never be hired or that lack the capacity and management for appropriate training may be irrelevant. The cause of failure may be at any one of these levels or several and that is why any solutions must address the whole system.

More detail for readers new to this subfield is presented in the Appendix to this article (Section I).

\subsection{Indicators in the field and the lack of an indicator for "capacity development" interventions}

Though there have been attempts to develop governance indicators for governance projects and diagnostics to use in planning capacity development interventions in different kinds of organizations, there are no existing indicators to score "capacity building" interventions on whether or not they are meeting the basic professional requirements of capacity building. Nor is there any licensing or grading system to measure basic competence or to establish other competence levels for practitioners who do "capacity building" and who claim to be "capacity building experts."

Among the most recent attempts, for example, the World Bank Institute has developed a manual but it is filled with dozens of questions to use and impossible to apply as a quick diagnostic (Otoo et al, 2009). Nothing else exists in the field. Though there are several international measures of "good governance" and "democracy" these do not cover the area of capacity building. Other measures, with community based organizations are closer to strategic management tools than capacity building measures (MicKinsey, 2001; Christensen et al., 2006; Gubbels and Koss, 2000; Lusthaus et al, 2002).

A review of these and others is presented briefly in the Appendix in Section II.

\subsection{The problem with many "capacity building" projects and the real value of an indicator}

In the absence of any professional standardization for use of the tool of capacity building or any accountability indicator for this approach, there is, in effect, no public review of the billions of dollars of public funds that are being transferred from developed countries to the governments and non-governmental institutions of the rest of the world in the guise of "capacity building." Abuses in this area are in fact running rampant. At best, "capacity development" projects are just throwing money at symptoms with no logic or analysis. At worst they are disguised bribes to 
government officials and attempts to undermine entire government structures by setting up foreign run Ministries and foreign influenced political parties or civil society to lobby for foreign interests.

These problems should be familiar to everyone in the field. In the Appendix, in Section III, some of the abuses are presented directly for readers, in stark terms. Although many of the descriptions are frank and direct, coming out of professional observations by the author in some 30 years in this field, the donors themselves admit the problems as well as the underlying goals of promoting their national self interest through aid as "soft power". They simply use more euphemistic language to soften the implications and potential exposure (Nye, 2004; Raffer and Singer, 1996; Mayo, 2009). The author has detailed some of these cases in greater detail in other works as well, including those referenced here.

Whatever the reasons for the failures, it is possible to use a simple tool to measure and expose the failures.

\subsection{The indicator of "capacity building" that can measure adherence to recognized professional standards of the field}

As a first step towards the licensing of practitioners who claim expertise in "capacity building" and as a way for citizens to hold donors accountable in the spending of their funds or in the acceptance of funds for "capacity building" while exposing approaches with hidden agendas, the indicator below is presented with 20 simple questions as a litmus test of basic competence in the field. By asking these 20 easy "Yes or No" questions and then counting up the results (possible 11 points), one can determine the relative competence and integrity of a "capacity building" project or intervention on the following scale:

Scale:

8 - 11 points Comprehensive approach to "capacity building" in ways that also appear to be promoting sustainable development, self reliance, and democracy in line with the Rio Declaration and International Conventions

4 - 7 points Minimally competent approach to "capacity building" with several

failures in procedure or safeguards

$0-3$ points Narrow or weak intervention

$<0 \quad$ Incompetent project with hidden agenda that has been corrupted either by the donor agency, stakeholders in a developing country bureaucracy, or both, in a possible attempt to purchase or influence foreign policies or to collude to misuse funds

Note that the indicator is not an absolute scale since it is not offered as a social science research tool (though it can be used as such) but as a project evaluation and selection tool. It is best used to show the relative value of different projects. The indicator does not measure the quality of specific capacity building, since that depends on many factors and comparisons, with benchmarks and cost-benefit analysis. It also does not measure how effectively a capacity building intervention is at promoting sustainable development, self-reliance, or democracy, since these are covered by other indicators, though a project that gets the highest score must at least be paying attention to these issues. The purpose of the indicator is not to measure "gross benefit" or "cost benefit." It is simply to measure compliance with professional standards for this type of intervention. Indeed, a capacity building initiative may be technically competent at building long term capacity but could still send a country down the wrong development path. That is why it is important to use this indicator in combination with others and why this indicator qualifies only as a litmus test for basic competence in use of this tool. (What the indicator does is 
determine whether the project is actually doing capacity building according to the technical standards of the tool or is hiding another objective. It also determines whether other agendas and ideologies have taken control of the funds and whether the overall goal is really to promote development and public control or not. It is essentially a litmus test of basic competence in the field and application of appropriate safeguards to protect professionalism and the public interest.)

Like most indicators, answers to each question would need to be "calibrated" to assure that different observers make the exact same determinations. To do so would require a longer manual for standardized, precise answers across observers.

\subsection{Measures/sub-factors}

Below, is an explanation of how anyone can apply the test to any project by asking the 20 questions and recording the scores. Most of the questions are clear cut "Yes" (1 point for applying a standard procedure, 0 loss of points for protecting against conflicts of interest or other corruption of standards) or "No" (0 points for failing to apply a standard procedure, -1 indicating a loss of points for facilitating conflicts of interest and corruption of standards), but in cases where there is a judgment call, you can opt for a "Debatable" ( 0.5 points for benefits and -0.5 points for harm).

The measures of performance can be placed into two categories that look at application of basic professional requirements for project design (positive scoring) and protection of the project in implementation from conflicts of interest or negative development impacts (negative scoring):

1) Proper Application of the Basic Principles and Standards of Capacity Building (5 of the 5 recognized principles of capacity building, including diagnostic of the three levels of analysis for capacity) and of Development Interventions, with the donor organization also serving as a model of accountability with a total of 11 questions broken into three sub-categories.

- The first sub-category (4 of the 5 recognized capacity building principles) looks at basic professionalism in diagnostic and design (7 questions for a possible 7 points).

- The second sub-category (the fifth of 5 capacity building principles), contingent on meeting the standards of the first category, addresses sustainability (2 questions for two possible points).

- The third sub-category addresses whether the donor or project implementing organization itself reflects and models the standards of good governance (2 questions for a possible 2 points or loss of 2 points).

(The overall potential scores for this section of 11 questions is 11 points.);

2) Professional Safeguards are in Place Against Conflicts of Interest and Against Unintended Consequences that could Distort other Public or Private Systems: with a total of 9 questions broken into two sub-categories.

- The first sub-category seeks to protect against conflicts of interest and against organizations searching for problems to fit the tool of "capacity building" or stakeholders to agree to projects (4 questions and a total loss of 4 points).

- The second sub-category seeks to protect against negative or adverse impacts on the overall political/government system and on related business and civil society systems (5 questions and a potential loss of 9 points).

(The overall potential score for this section of 9 questions is to maintain the points awarded in the first section.) 
The first category (and particularly the first sub-category of 7 questions) is itself a screening to test whether a project actually achieves anything in the area of capacity building at all, and whether it meets minimal basic competence in the field.

Questions marked with an asterisk (*) are those that apply to any development intervention. They represent the basic steps of project design (root cause analysis; benchmarks and cost benefit of interventions that are tied to specific measurable results and indicators; sustainability of the input), of screening to assure appropriate development impact, and tests of the donor organization to assure best practices are followed.

Note that some of the questions below may seem lengthy, and this "simple" list may not look that easy to use on first glance. The questions are lengthy so that the goal of each question is clear and readers can train themselves to effectively score the question. With some short practice (working through the example in the Appendix, in Section $V$, and also considering the scoring for several projects, presented in the Appendix, in Section IV), readers will be able to see how the indicator works to distinguish interventions and to offer a valid way to score and improve them.

1. Proper Application of the Basic Principles and Standards of Capacity Building (5 of the 5 recognized principles of capacity building, including diagnostic of the three levels of analysis of capacity) and of Development Interventions with the donor organization also serving as a model of accountability: This is the category that can be used for screening whether the project and spending really have any substance and fit the basic professional competence of capacity building and of development interventions. (11 questions and a potential score of 11 points) A project that does not score more than 4 points in this category is already partly suspect as being driven by an outside agenda to favour a specific group rather than to promote real democratization and good governance. At least 5 of these questions (marked with an asterisk) are directly applicable to any development intervention. The other 6 are specifically applicable to "capacity building" though they could also be applicable to other development interventions with slight modification.

1.a) Project Meets 4 of 5 of the Recognized Principles of Capacity Building, including diagnostic of the three levels of analysis of capacity, and Principles of Professionalism for Development Interventions: This is the heart of the indicator. A project that does not score at least 4 points here is probably not competent in the field. ( 7 questions and a potential score of 7 points)

\section{Question 1*:}

Country and Cultural Fit of the Development Intervention for Sustainable Development: Fixing what is Broken. The project is not formulaic or sector specific ("to train judges"; "to build a modern X system") but is fit specifically into the local cultures and their needs for maintaining or returning to sustainability and fixing a system that has broken, with the analysis beginning with an assessment of local needs. The question is whether the capacity building is relevant to restore the sustainability of the local culture(s) and repairs an existing and identifiable underlying problem that has moved the culture away from sustainability and needs to be "fixed" in line with international principles of cultural survival and sustainable development. The overall approach carefully incorporates the requirements of sustainable development established by the Rio Declaration (balance of population and consumption with productivity and resources) in its approach to governance as the basic principle of the role of governance in sustainable development (United Nations Conference on Environment and Development ${ }^{42}$; United Nations

\footnotetext{
42 U.N. Declaration on the Rights of Indigenous Peoples (2008) URL (consulted 17 June 2015):
} http://daccessdds.un.org/doc/UNDOC/GEN/N06/512/07/PDF/N0651207.pdf?OpenElement. 
Declaration on the Rights of Indigenous Peoples ${ }^{43}$ ). If the approach is one that simply targets a "sector" in a "sector wide approach," and/or that is an outside determination based on a formula or a comparison with what "developed" countries or cultures have, then the score here is zero because it has not started with the cultural fit as a whole and may simply be developing one system to the detriment of the overall balance for sustainability and appropriate governance. (For expanded applications, see Lempert and Nguyen, 2008.)

$$
\begin{array}{ll}
\text { Scoring: } & \text { Yes }-1 \\
& \text { Debatable }-0.5 \\
& \text { No }-0
\end{array}
$$

\section{Question 2*:}

Governance or Civil Society Functions Promoted are Appropriate Parts of the Key Governmental or Non-Governmental Organizational Missions through which there is Direct Public Accountability. The project is clearly designed to promote either a specific government function of protecting and/or promoting (separately and as a competing function in a structured system) an asset or resource of specific ethnic groups and of the country in ways that maintain or increase the per capita assets of the culture and the country, or to promote a non-governmental organization function that is specifically separate from government and which is directly accountable to all of its owner, consumer, neighbour stakeholders. There is a clear and measurable mission of accountable governance with measurable costs and benefits to specific units of public spending or resources for which specific government or non-government officials can be held directly accountable by citizens (removal, punishment, or rewards). Interventions that "promote regional integration" or "monitor foreign development funds" or "strengthen civil society" do not earn points. Government missions should be to "promote, measure, and maintain" assets. Those that "promote justice" or "improve health" or "protect resources" but do not assure that there are measurable benefits to specific cultures and/or per capita long-term improvement that are appropriate to their sustainability and adaptability, or that "develop" a resource without also protecting it, may actually distort effective governance systems and earn no points.

$$
\begin{array}{ll}
\text { Scoring: } & \text { Yes }-1 \\
& \text { Debatable }-0.5
\end{array}
$$$$
\text { No - } 0
$$

\section{Question 3:}

Full Framework Analysis Includes Three of the Multiple Dimensions or Levels of Capacity to Determine All of the Failures and their Relationships to Each Other. Regardless of any initial area that the project might pre-select as an intervention, the project withholds judgment on the nature of solutions or problem and conducts a full diagnosis to get at the root causes of the failures. The project design includes a thorough assessment of the multiple dimensions of "capacity" that includes all of the following as a key to understanding the human dimensions and behaviours that are the source of failures of systems to meet needs for sustainable development 1) the societal and cultural level, including ideologies, mal-adaptations to environmental changes, distributions of power and organization of political and

\footnotetext{
43 United Nations Conference on Environment and Development (1992) Rio Declaration on Environment and Development. URL (consulted 17 June http://www.un.org/documents/ga/conf151/aconf15126-1annex1.htm.
} 
legal institutions (including legacies of colonialism or current outside pressures) that interfere with sustainability; 2) failures at the organizational and institutional level for fulfilling specific missions; and 3) human resources failures. The analysis distinguishes symptoms from causes and also models how the entire system would work if it were returned or moved towards sustainability. There is commentary on the status of each of the four areas indicating whether or not there are failures at each level and determining with evidence whether or not specific areas can be approached independently to reach solutions or whether only comprehensive and linked solutions can achieve solutions to the problem and move towards a sustainable model.

Scoring: $\quad$ Yes -1 (All four of the levels are fully considered)

Debatable - 0.5 (All four levels are considered but measures may be sloppy.)

No - 0

\section{Question 4*:}

Root Cause Analysis and Problem Trees. The project focuses on those areas where there are failures and where specific and comprehensive changes can lead to measurable performance improvements. The project design includes a thorough assessment of the root causes for the failures that can be corrected through "building capacity." Problems are mapped in a problem tree and the root causes of the problem, with identifiable target ACTORS whose behaviours need to be changed, are presented in a systematic and linked way. The potential intervention is tied directly to the problems at every one of the identified steps in the sequence where there are failures, with specific measurable outputs per unit of input at each stage, with particular attention to human behaviours at various levels to be changed that underlie the problem (rather than symptoms of weaknesses) that lead to measurable performance outcomes/results. Symptoms (low skills; lack of transparency or incentives, weak management, low resources) are not root causes, only individual and social and organizational behaviours are, and these are fully recognized in a problem statement and root cause analysis. The logframe shows specific measurable behaviour changes in cost savings, cost effectiveness, and other service delivery and social indicators, as direct output evidence of performance improvement outcomes, rather than simply throw inputs at a symptom and assume that there will be "better governance" or "improvement" or "greater capacity" or "more efficiency" because resources have been transferred.

Scoring: $\quad$ Yes -1

Debatable -0.5

No - 0 (No problem statement or Root Cause or Problem Tree)

\section{Question 5*:}

Logframe Specifically Targets the Root Causes in an Appropriate Sequence, Showing How Specific Measured Inputs Lead to Specific Measured Performance Changes Over a Long Period of Time, with Cost Effectiveness Ratios of Inputs to Outputs Included Based on Benchmarks of Outcomes. The project logframe demonstrates specific measurable behaviour changes as outputs that lead to performance improvements, rather than simply throws inputs at symptoms and assumes that there will be "better governance" or "improvement" or "greater capacity" because resources have been transferred, documents have been drafted (laws, action plans or policies), agreements have been signed, people have been "trained," or new offices or institutions have been established or tasked. Inputs are not turned into outputs because they are delivered or received or because something is to be produced. To earn points there must be clear benchmarks of 
changed service delivery that are not simply accounting measures of delivery of inputs or intermediate inputs and there should be benchmarks linking units of spending to specific behavioural changes of specific numbers of a target population, with those specific behaviours leading to performance results that move a culture back to a path of sustainable development (living within its resource base).

Scoring: $\quad$ Yes -1

Debatable -0.5

No - 0 (No cost benefit analysis of outputs; no logframe or logframe where inputs and outputs are confused and do not meet professional standards)

\section{Question 6:}

Public Accountability Mechanisms are Part of the Assessment (Fourth Principle of Capacity Building, in Analysis) and the Project Begins with Concern of Placing Capacity in Public Hands, Starting with Youth as the First and Priority Alternative of any Capacity Building Intervention. The project design includes a thorough assessment of the accountability of the systems to the public as a key to the social context. There is a focus on the laws, the incentives of officials, the feedback for funding, the monitoring of funds, and the public tasking and monitoring of results of the institutions for which capacity is to be "built." There is a focus on increasing the capacity of the public, first, since all government and non-governmental functions and cultural decisions and understandings ultimately depend on the skills of the public. Building capacity of the public is considered first before any decision is made to work directly with the public's agents or representatives, in order to ensure that specialists will be fully accountable to and controlled by the public. Projects to build civil society or governance start with assessments of the general skills, powers, and capacities in the population for such oversight and works to built them at the level of basic socializing institutions with young people, first, rather than with adults. The project clearly explains any decisions not to put all such skills and capacities into the public starting with youth and in models with youth (model civic actions and democratic governance of youth, model youth courts and public investigations, youth newspapers and NGOs, youth businesses, etc.)

Scoring: $\quad$ Yes -1

$$
\text { Debatable }-0.5
$$

No - 0

\section{Question 7:}

Agreement is Transparent to Citizens and they are Included in the Project Oversight and Approval (Fourth Principle of Capacity Building, in Implementation). The project transfer of inputs to government or NGO stakeholders is conducted in ways that include screening and monitoring directly by citizens of the host population, including not only the direct approval of their legislative bodies but openness to media and outreach and inclusion of the public, so as to avoid any agreements that are government to government or bureaucrat to bureaucrat transfers.

Scoring: $\quad$ Yes -1 , if the project shows awareness of this and protects against harm

Debatable or not relevant - 0

No - (-1) (Loss of a point) 
1.b) Sustainability of the Impact through Systematization and Institutionalization: The Fifth Principle of Capacity Building and One Common to Other Development Interventions: The project doesn't just seek short-term impact but institutionalizes a process of continued responsiveness and adjustments of capacity, as well as identification of needs and building of new capacity, in the governmental system and/or culture. (2 questions and a potential score of 2 points, to be awarded ONLY if the project has achieved a score of at least 4 points on the first 7 questions. Otherwise the measures are rewarding sustainability of a project that may actually undermine appropriate capacity building.)

\section{Question 8:}

Intervention Institutionalizes Change at the Root of the Problem, Fixing a Broken System, and is Not Funding an Institution or Activity for a Problem that Starts Elsewhere in the Society or Culture (e.g. Offering Remedial Training of Adults, Professionals or Employees). The project repairs a system failure (e.g., basic parental or public education for adult responsibilities; university education; professional education; a personnel selection system; salary structure; information system) and assures that is adaptive to change, for multi-generational continuing impact rather than offering a short term transfer or quick fix to one target stakeholder or recipient group. An education problem in skills, an awareness or consciousness issue, an issue of funding or overall behaviours, is traced back to family socialization and the formal and informal (media) education system with a focus on changing those for the long term rather than simply treating the symptom by working with adults.

$$
\begin{array}{ll}
\text { Scoring: } & \text { Yes }-1 \\
& \text { Debatable }-0.5
\end{array}
$$$$
\text { No - } 0
$$

\section{Question 9*:}

Sustainability of the intervention and Impact. The Intervention Builds a Continuing System of Measurement, Monitoring, Determining of Actual Need and Value, and Appropriate Advocacy and Receipt of Future Funding. The intervention has built institutional mechanisms that are self-sustainable within the country's resources and have continued local financing and management, with freedom from continued foreign or institutional funding that would create dependency on outsiders for achievement of the project goals. The project builds and institutionalizes an incountry monitoring system of capacity and of costs and benefits in the services that are being supported, such that the system adapts to changing conditions and measures (with adequate oversight to assure no conflicts of interest in the data) that there is appropriate advocacy for funds and receipt of support in an effective balance with other competing systems through a fair process. There is a specific determination of "how much" capacity is needed to solve a particular problem and at a measurable cost, with costs and benefits considered to the country and how the country will be able to pay for it out of the stream of future benefits. It is not just considered to be good for its own sake, without justification.

$$
\begin{array}{ll}
\text { Scoring: } & \text { Yes }-1 \\
& \text { Debatable }-0.5 \\
& \text { No }-0
\end{array}
$$

1.c) Internal Procedures of the Project, Itself, Reflect the Values of Accountability and Self-Reliance: The project organization is itself a model of good governance, accountability, efficiency, transparency and appropriate capacity (2 questions and a potential score of 2 points but also a potential loss of 2 points if the project itself sends a message that contradicts and undermines what it claims to be achieving) 


\section{Question 10:}

Accountability of the donors: The project itself (the donor organization) is a model of transparency and direct accountability to beneficiaries and to citizens, and does not hide behind barriers that require citizens or beneficiaries to demand that government representatives or other elites bestow accountability. Projects that meet this requirement will have open books, clear professional ethics codes, full published reports on their projects, and full use of measurement tools of benefits in the profession (cost-benefit, baselines, comparative indicators, and industry benchmarks). Moreover, the donor organization, itself, has conducted the very same capacity analysis subject to the same questions as in this test, to assure that it has a clear and strategic mission, that its own results are measurable with benchmarks and cost effectiveness data, that its employees meet specific tests of certified competence in their fields, that evaluations are done independently and objectively not with management oversight but with the oversight of funders and beneficiary stakeholders, with results available and with feedback systems that assure accountability and implementation of the results.

Scoring: $\quad$ Yes -1 , if the project shows awareness of this and protects against harm

Debatable or not relevant - 0

No $-(-1)$ (Loss of a point)

\section{Question 11:}

Rewards and Incentives: The project rewards behaviours that promote independence and sustainability of recipients and punishes behaviours that promote dependency or donor relationships, with no opportunity for collusion to prolong funding in the absence of meeting stringent conditions for results, established in advance. Delayed projects are not rewarded because of good "relationships" have been built and officials or beneficiaries "appreciate" the assistance, but because there are clear standards showing progress towards measurable results and sustainability and that exceed standard benchmarks for projects resolving similar root causes of the problems. Grants are given with real conditions that have enforceability and consequences without paternalistic justifications that recipients cannot or should not be held to real standards. Success of a project does not lead to replication in additional areas using more outside funds but towards promotion of copying by others with their own resources. Failure of a project to be sustainable or to show strong benefits does not invite additional funding because of "continued poverty" or "need" but triggers an immediate change and possible liability. The original setting of conditions on the project meets the most stringent of international treaty standards, benchmarks and objectives and was not simply a politically negotiated transfer of support to facilitate project inception.

Scoring: $\quad$ Yes -1 , if the project shows awareness of this and protects against harm

Debatable or not relevant - 0

No - (-1) (Loss of a point)

2. Professional Safeguards are in Place Against Conflicts of Interest and Against Unintended Consequences that could Distort other Public or Private Systems: These questions are challenge tests to assure that the design process is actually being used in ways that it is supposed to work. For this reason, scoring here is negative, subtracting points for failures. Questions are in two categories: 4 questions on conflicts of interest and 5 questions on negative impacts on public and private systems. (9 questions and a potential loss of 9 points) 
2.a) The "Capacity Building" Tool is One Tool to Fit an Objectively Measured Sustainable Development Need, Rather than a Tool Searching for a Need Where it Can Be Used or as a Political Facilitator of Some Other Transfer: No Conflicts of Interest: The project is not subject to the influence of any stakeholder groups in its design or implementation other than determinations of independent professionals held directly accountable to ethics standards (4 questions and a potential loss of 4 points)

\section{Question 12:}

Assessment of the Need is Protected Against Subjective Biases of the Partners/ Stakeholder Recipients. The project clearly distinguishes the difference between sustainable development "needs" and partner/stakeholder "wants." Needs for capacity building are assessed as relevant to fixing a root cause of a development problem with failures assessed before the project begins and before any funds are committed, using independent, objective measures such as skills testing, production and service analyses, monitoring of performance and outputs, strategic management tools (for potential consulting inputs), etc. The project is not a Santa Claus, measuring its success with "smile sheets" of how happy partners or stakeholder recipients are to receive support and asking them to measure their "needs" with questionnaires or group meetings (what they would "like to learn" or where they could "use consultants") in ways that offer funds first and then seek to justify their transfer with the subjective or political determinations.

Scoring: $\quad$ Yes -0 (no loss of points), if the project shows awareness of this and protects against harm

No explicit policy at the organization to protect against this, but no clear sign that abuse has occurred - $(-0.5)$ (Loss of half of a point)

No, and there are signs that this abuse has occurred or is very likely to occur - (-1) (Loss of a point)

\section{Question 13:}

Delivery of Inputs Does Not Personally Benefit the Stakeholders/Partners but Benefits Everyone in the Society/Culture Equally. The project includes no incentive payments in the form of perquisites to convince or ease participation of officials (per diems or other payments that are above salary; travel and tours; scholarships and education resulting in degrees or certificates that can be used in other jobs; vehicles, computers, or other office equipment). Anything delivered is measured in a specific test of benefits to the country versus benefits to the implementing stakeholders. Such payments and transfers are also those that members of the public are informed about and approve.

Scoring: $\quad$ Yes -0 (no loss of points), if the project shows awareness of this and protects against harm

No explicit policy at the organization to protect against this, but no clear sign that abuse has occurred - $(-0.5)$ (Loss of half of a point)

No, and there are signs that this abuse has occurred or is very likely to occur - (-1) (Loss of a point)

\section{Question 14:}

There are No Linked Inputs or Grant Funds for Officials to Manage that do Not Directly Improve Capacity for Already Existing Budgets and Target Root Causes of Capacity Failures Rather than Symptoms. The project includes no pump priming grants to government agencies that increases their existing budgets without starting directly on the root causes of administrative system failures. Anything delivered is measured in a specific test of solving the problem of current lack of 
capacity for managing existing budgets or for making the case for increased taxation rather than as a sweetener that could hide another objective. Questions are asked immediately about why the agency currently does not tax effectively for funds if they do lead to public benefit, or why they have not closed loopholes of corruption or established appropriate development priorities, before anything is given to a partner to manage.

Scoring: $\quad$ Yes -0 (no loss of points), if the project shows awareness of this and protects against harm

No explicit policy at the organization to protect against this, but no clear sign that abuse has occurred $-(-0.5)$ (Loss of half of a point)

No, and there are signs that this abuse has occurred or is very likely to occur - (-1) (Loss of a point)

\section{Question 15:}

Screening and Delineation of All Conflicts of Interest of International "Partner" Organizations for "Twinning" Projects, for Consultants and International Firms, and of all Implementing and Donor Agents/ Stakeholders is Combined with Legal and Ethical Oversight. The project documents all possible biases and benefits to the participating partners, donor agents, and donor staff to assure that there are no future financial or personal benefit conflicts of interest beyond pure humanitarian goals driving projects or methods for specific benefits to stakeholders that are in any conflict with the funders and/or the public beneficiaries that drive project decisions in any way. Strict mechanisms are in place for outside challenges, for review, and for stopping projects or penalizing offenders for any such conflicts.

Scoring: $\quad$ Yes -0 (no loss of points), if the project shows awareness of this and protects against harm

No explicit policy at the organization to protect against this, but no clear sign that abuse has occurred - (-0.5) (Loss of half of a point)

No, and there are signs that this abuse has occurred or is very likely to occur - (-1) (Loss of a point)

2.b) No Negative or Adverse Impacts on the Political/Government System or on Related Private Systems: The project does not distort the overall governmental system or the roles or balance of governmental or non-governmental (business and community based) institutions but supports their appropriate roles. (5 questions and a potential loss of 5 points)

\section{Question 16:}

Citizen powers and enforceable protections are Strengthened as the Initial and Linked Goal and Result of All Interventions, with Real Safeguards Against Transferring new powers to officials or to large private organizations (business or civil society, including foreign government, business and NGO actors) in the Name of Citizen Protection, or any other changes making decisions more opaque or hierarchical. The project does not increase the power of officials or designated representatives over citizens (e.g., supporting strengthening of an "institution" that empowers its officials such as Parliament or an "Ombudsman" or "Prosecutor" rather than increasing the role of the public using the government function, such as empowering the public with legislative power and skills, increasing public ability to sue and remove government officials and to be the judicial deciders, or allowing for class action suits and other "private prosecutor" mechanisms.) The intervention does not create new public bureaucracies without a real change in citizen power.

Scoring: $\quad$ Yes -0 (no loss of points), if the project shows awareness of this and protects against harm 
No explicit policy at the organization to protect against this, but no clear sign that abuse has occurred - $(-0.5)$ (Loss of half of a point)

No, and there are signs that this abuse has occurred or is very likely to occur - (-1) (Loss of a point)

\section{Question 17:}

Interventions do not Improve Efficiency of Systems that May be Undemocratic, Inequitable or Unjust but Begin with a Focus on Accountability, Participation, and Equity. The project recognizes the danger of "efficiency" of systems that are inherently unrepresentative and does not simply promote efficiency given the potential for continued rights abuses by an authoritarian or unaccountable regime. Projects working with businesses, community based organizations or any aspects of government where decisions are made (particularly the justice system but also Parliament and any Ministries with discretionary and/or policy authority) work to link efficiency interventions directly with equity and direct citizen control (removal, sanctions, legal challenges, equal participation as jurors).

Scoring: $\quad$ Yes -0 (no loss of points), if the project shows awareness of this and protects against harm

No explicit policy at the organization to protect against this, but no clear sign that abuse has occurred - $(-0.5)$ (Loss of half of a point)

No, and there are signs that this abuse has occurred or is very likely to occur - (-1) (Loss of a point)

\section{Question 18:}

Donor-to-Stakeholder Beneficiary Financial Transfers (Grant, Loan, Gift) or Commitments that are Given as Part of "Capacity Building" Do Not Create Future Obligations in Ways that Could Subsidize a Favoured Social Group, Distort Taxes, or Negatively Influence Priorities for Sustainability. The project meets strict public finance criteria for grant, loan/investment, or subsidy and funds are allocated appropriately, with public oversight to assure that any loans are approved by the public and that the public is able and willing to pay for each item that is linked to "capacity building." The impact of the assistance does not end up subsidizing some other improper spending (allowing a transfer from one category of spending into something else as a result of the gift), reducing pressure on elites who should tax themselves to fund the project, or end up distorting capital markets in the country by offering a gift or subsidy for a kind of productive investment that should be in the form of a loan or in the form of a loan at competitive market rates. If the project merely seeks to find "poor" people to help by building the "capacity" to help them, but does not analyze the responsibility of the elites in the country to fulfill obligations of social solidarity with people in their own country, the project is part of a collusion in detaching elites globally from their local responsibilities and has a negative impact. If the project does not do an analysis of existing government spending and tax policies, it is likely that the project is offering money for the "poor" at the same time that an excessive amount of the budget is being used for military and police spending to control the poor, and the project is actually subsidizing this pattern. If the project includes a gift rather than a loan and does not include standard financial controls and conditions, it is likely being given with the knowledge that corruption will occur and as a subsidy for corruption and waste, including purchase of luxuries and foreign goods.

Scoring: $\quad$ Yes -0 (no loss of points), if the project shows awareness of this and protects against harm

No explicit policy at the organization to protect against this, but no clear sign that abuse has occurred $-(-0.5)$ (Loss of half of a point) 
No, and there are signs that this abuse has occurred or is very likely to occur - (-1) (Loss of a point)

\section{Question 19:}

Government functions are respected and the balance with civil society is promoted appropriately and internally, with effective public regulation of the nongovernmental sectors. The intervention does not replace a government function with foreign paternalism building parallel systems that are better than government but that do not improve what is wrong, or transfer a government function to another place like civil society because of current underperformance. Nor does the project seek to build a civil society that must rely on funds from donors or from elites, in place of direct support and control by the beneficiaries, themselves. Nor does it seek to build a strong private sector without effective public regulation of that sector and restrictions on the powers it could exert through financial pressures. (NGOs are not public service providers but provide for private needs and have a role in trying to improve government action; businesses are not "corporate citizens" but are producers to be taxed and regulated to fund public functions, etc. The appropriate role of an NGO is to model a new behaviour to try to convince government to change, and to advocate for the special interests of a group with sustainable funding and accountability to that beneficiary group, but not reliant on foreign or other outside funding. The appropriate role of funding for NGOs must also be to ensure that they are sustainable with funding from the beneficiaries and with accountability directly to the beneficiaries, and not dependent on funds from foreigners or from elites who are disconnected to benefits to the beneficiaries and who have different interests.)

Scoring: $\quad$ Yes -0 (no loss of points), if the project shows awareness of this and protects against harm

No explicit policy at the organization to protect against this, but no clear sign that abuse has occurred - (-0.5) (Loss of half of a point)

No, and there are signs that this abuse has occurred or is very likely to occur - (-1) (Loss of a point)

\section{Question 20:}

The Intervention Promotes Competition Among Providers in the Area where Capacity is Built and Does Not Distort Market Systems. The project seeks to build the infrastructure in society for government consulting, training systems/ educational institutions, information systems and other organizations that public institutions can hire and fund through competitive bids, and does not seek to monopolize a particular training or provide it directly where such services can be provided. Donors do not pick "winner" NGOs or businesses or agencies to receive support in ways that could disfavour competitors from developing. An assessment is done at the beginning of the project of the means of developing this kind of service market for the capacity needs of governmental and non-governmental organizations (following a Business Development Services (BDS) model).

Scoring: $\quad$ Yes -0 (no loss of points), if the project shows awareness of this and protects against harm

No explicit policy at the organization to protect against this, but no clear sign that abuse has occurred - (-0.5) (Loss of half of a point)

No, and there are signs that this abuse has occurred or is very likely to occur - (-1) (Loss of a point) 


\subsection{How some organizations do}

After understanding how the indicator works, it is easy to apply to every new case in just a few minutes and with close agreement among anyone using it. In the Appendix, in Section IV, are several examples including many of the standard approaches that are now widespread in the field, showing how different organizations and projects score, from best to worst. Rather than score specific projects in particular countries, some of the projects are generalized in project categories that are common in the field, showing the range of scores that they earn depending on which particular features are included in certain types of projects by specific donors and proponents.

\section{Post-script: solutions}

The irony of exposing the flaws in development projects today is that the "experts" who are in the position to make changes have little incentive to change, while those who are best protected by change are the least informed and organized about where or how to begin to push for reforms. An indicator can facilitate change, but like other improved tools, it must be in the hands of those willing and able to use it.

Organizations that score the worst on the new indicator in this article will likely not even recognize their failures. (They are likely to say that professional compliance standards do not apply or that projects are "too diverse" or that measurement is "too difficult" or "subjective". They may say that this business-like approach that introduces a variety of professional expertise takes the artistry and "humanistic" or "human" judgment out of their work, though in fact it does the opposite by applying their own standards to their work. They are likely to respond defensively to suggestions for more public oversight of their work and to claim that accountability is a form of "policing," even though they accept the idea of "accountability" as one of the key principles of effective capacity building. They are likely to say that oversight implies "mistrust" and that their good faith is being questioned, in the premise that they are above the law and the public is (by their design) ignorant and uninformed about what they do. They may say that holding a government official accountable for results is unfair because there are "too many factors")

Overall, such responses from many "professionals" in "good governance" will demonstrate exactly why many of the people in place in current systems are part of the problem and not the solution. Indeed, the only real solution is mobilization of the public.

This author has suggested the formation of Donor Monitor NGOs that act as public advocates (Lempert, 2008) and has designed a full set of other governance reforms in media, organizational oversight, private attorneys general and other citizen powers that would promote professionalism and accountability at the level of constitutional changes (Lempert, 1997) as well as educational and cultural reforms. But who will fund and promote them?

In short, foxes have entered the henhouse in design and implementation of capacity building projects in international development as well as many other governmental systems, and there is a need to devise better oversight systems. The only way that change can really occur is if those public voices who have an interest in the oversight act collectively to protect their interests. In the case of capacity building for "governance" those interests are a stable and democratic world as well as control over billions of dollars in public money that is diverted.

This article offers one tool, a weapon of empowerment, to at least facilitate that effort, as part of a codification of laws and standards that could ultimately be enforceable both by those paying for the interventions and those at the receiving end. This indicator takes away excuses that oversight is too difficult for ordinary citizens and that we must simply wait, pray, and rely on experts to change in ways 
they have little incentive to change, rather than to take on the burdens of citizenship to protect the public interest in promoting effective, efficient and law abiding development interventions.

\section{References}

Acharya, Meena and Art Wright (2000) 'An Evaluation of the Impact of the United Nations System on Capacity Building for Poverty Eradication', A report for the Department of Economic and Social Affairs of the United Nations, December 15.

Boesen, Nils and Ole Therkildsen (2004) Between Naivety and Cynicism: A Pragmatic Approach to Donor Support for Public- Sector Capacity Development. Copenhagen: Ministry of Foreign Affairs.

Boesen, Nils, Peter Christensen and Ole Therkildsen, Ole. (2002) 'Evaluation of Capacity Development in a Sector Programme Support Context: Contributions to an Analytical Framework', Copenhagen: Danish International Development Agency (DANIDA). URL (consulted 17 June 2015): http://www.um.dk/Publikationer/Danida/English/Evaluations/CapacityDevelopment2 00501/11636_cdoe_asp/annex1.asp

Busan Partnership for Effective Development Cooperation. (2011) 'Fourth High Level Forum on Aid Effectiveness', URL (consulted 17 June2015): http://effectivecooperation.org/resources/

Ember, Carol R. and Melvin R. Embert (2006) Cultural Anthropology. $12^{\text {th }}$ edition. United States: Prentice Hall.

Christensen, Robert K., Helen K. Liu, Stephanie Moulton, Becky Nesbit and Eva Witesman (2006) 'Assessing the Effectiveness of Capacity Measures and Frameworks in Public and Nonprofit Performance Evaluation', URL (consulted 17 June 2015): http://arnova.omnibooksonline.com/2006/data/papers/PN062016.2.pdf

Consulting, Elton (2002) 'The Bronte Catchment Project: A Case Study in Capacity Building', Elton Consulting March 2002. URL (consulted 17 June 2015): http://www.elton.com.au/pdfs/capacity.pdf

Dresang, Dennis L. (2009) Personnel Management in Government Agencies and Non-Profit Organizations. London: Longman.

Enemark, Stig (2003) 'Best Practice in Capacity Building: Understanding the Concept of Capacity Building and the Nature of Land Administration Systems', FIG Working Week, Paris, France.

Emmanuel, Clive, Kennet Merchant and David Otley (1990) Accounting for Management Control. London: Chapman \& Hall.

European Commission (undated, accessed in 2003) Handbook on Promoting Good Governance in EC Development and Cooperation. European Aid Cooperation Office, publication J54-07/20.

European Commission (2002) Measuring Democracy and Good Governance. Conference, Munich. URL (consulted 17 June 2015): http://www.inwent.org/imperia/md/content/bereich4-intranet/abteilung4-06/d1.pdf

Forrester, Jay (1994) 'Systems Dynamics, Systems Thinking and Soft OR', System Dynamics Review 10(2):245-256.

Freedom House. (2006) Methodology. URL (consulted 17 June 2015): $\mathrm{http}: / / \mathrm{www}$.freedomhouse.org/template.cfm?page $=352 \&$ ana_page $=330 \&$ year $=200$ 6

Garrison, Ray H., Eric Noreen and Peter C. Brewer (2005) Managerial Accounting. New York: McGraw-Hill Irwin. 
Gubbels, Peter and Catheryn Koss (2000) From the Roots Up: Strengthening Organizational Capacity through Guided Self-Assessment. Oklahoma: World Neighbors.

Honadle, Beth Walter (1981) 'A Capacity Building Framework: A Search for Concept an Purpose', Public Administration Review 41(5): 575-580.

Kaufmann, Daniel, Aart Kraay and Massimo Mastruzzi (2007) 'Governance Matters VI: Aggregate and Individual Governance Indicators 1996-2006', The World Bank, Policy Research Working Paper, No. 4280.

Kekic, Laza. (2007) 'The Economist Intelligence Unit's Index of Democracy', URL (consulted 17 June 2015): http://www.economist.com/media/pdf/DEMOCRACY_INDEX_2007_v3.pdf

Lempert, David (1997) 'Holding the Powers that Be Accountable to Our Ethics Code to Protect Our Integrity and the Peoples We Serve', Human Rights 24(2):2224.

Lempert, David (2008) 'Why We Need an International Development Donor Monitor', Policy Innovations. URL (consulted 17 June 2015): http://www.policyinnovations.org/ideas/policy_library/data/01464

Lempert, David (2009a) 'A Dependency in Development Indicator for NGOs and International Organizations', Global Jurist 9(2). URL (consulted 17 June 2015): http://www.degruyter.com/view/j/gj.2009.9.2/gj.2009.9.2.1296/gj.2009.9.2.1296.xml ?format=INT

Lempert, David (2009b) 'Why Government and NGO Projects Fail Despite 'Evaluations': An Indicator to Measure whether Evaluation Systems Incorporate the Rules of Good Governance', Journal of Multi-disciplinary Evaluation 6(13):58-108.

Lempert, David. (2010a) 'A Human Rights Education Project Indicator for NGOs and International Organizations', Interamerican Journal of Education for Democracy 3(1): 45-72.

Lempert, David (2011) 'Democracy Building Democratic Project Indicators for NGOs and International Organizations', Global Jurist 11(2) DOI: 10.2202/19342640.1385

Lempert, David (2012) 'A Quick Indicator of Effectiveness of "Income Generation" and "Sustainable Business Initiatives" in International Development', Economology Journal 2(2):28-90.

Lempert, David (2014) 'Universal Development Goals for This Millennium', Consilience: The Journal of Sustainable Development 12(1): 1-24.

Lempert, David (1996) Escape From the Ivory Tower: Student Adventures in Democratic Experiential Education. Michigan: Jossey-Bass Publishers.

Lempert, David, Nguyen, Hue Nhu (2008) 'How to Tell if Development Projects are Doing Sustainable Development: An Indicator for NGOs and International Organizations', International Journal of Sustainable Societies 1(1):44-54.

Linnell, Deborah (2003) Evaluation of Capacity Building: Lessons from the Field. Washington: Alliance for Nonprofit Management.

Lusthaus, Charles, Marie-Hélène Adrien, Gary Anderson, Fred Garden and George P. Montalván (eds) (2002) Organizational Assessment: A Framework for Improving Performance. New York: International Development Research Centre.

Marshall, Monty, Keith Jaggers and Ted R. Gurr (2006) Polity IV Project: Political Regime Characteristics and Transitions 1800-2006. URL (consulted 17 June 2015): http://www.systemicpeace.org/polity/polity4.htm 
Mayo, Dambisa (2009) Dead Aid: Why Aid is Not Working and How there is a Better Way for Africa. New York: Farrar, Straus and Giroux,

McKinsey and Company and Venture Philanthropy Partners (2001) Effective Capacity Building in Non-Profit Organisations. URL (consulted 17 June 2015): http://74.125.153.132/search?q=cache:PX5FOlpU-

5YJ:venturephilanthropypartners.org/learning/reports/capacity/full_rpt.pdf+Effective +Capacity+Building+in+Non-

Profit+Organisations.+McKinsey+and+Company. $+2001 \& \mathrm{~cd}=1 \& \mathrm{hl}=\mathrm{en} \& \mathrm{ct}=\mathrm{clnk}$

Measure Evaluation (1999) Measuring Capacity Building in Health and Population Programs," Conference Proceedings for U.S. Agency for International Development. Arlington, Virginia. URL (consulted 17 June 2015): http://pdf.usaid.gov/pdf_docs/Pnacj170.pdf

Muller, Duane (2007) USAID's Approach to Monitoring Capacity Building Activities: Experiences, Lessons Learned, and Best Practices. URL (consulted 17 June 2015):

http://74.125.155.132/search?q=cache:VrmLlor3eqwJ:www.encora.eu/coastalwiki/l nstitutional_Capacity_Building+institutional+capacity+building\&cd $=5 \& \mathrm{hl}=\mathrm{en} \& \mathrm{ct}=\mathrm{cln}$ k.

Musgrave, Richard and Peggy B. Musgrave (1973) Public Finance in Theory and Practice. New York: McGraw Hill.

Nelson, Debra L., James C. Quick (2005) Understanding Organizational Behavior. Mason: Thomson South-Western, $2^{\text {nd }}$ edition.

Noe, Raymont A., John R. Hollenbeck, Barry Gerhart and Patrick M. Wright (2007) Human Resources Management. New York: McGraw Hill.

Nye, Joseph S. (2004) Soft Power: The Means to Success in World Politics. New York: Public Affairs.

Ogiogio, Gene (2005) 'Measuring Performance of Interventions in Capacity Building: Some Fundamentals', Africa Capacity Building Foundation, Occasional Paper No 4.

Organization for Economic Cooperation and Development. (2008) Aid Targets Slipping Out of Reach? France: Paris. URL (consulted 17 June 2015): http://www.oecd.org/dataoecd/47/25/41724314.pdf

Otoo, Samuel, Natalia Agapitova and Joy Behrens (2009) The Capacity Development Results Framework. A strategic and results-oriented approach to learning for capacity. Washington D.C.: The World Bank.

Paris Declaration on Aid Effectiveness. (2005) URL (consulted 17 June 2015): http://www.oecd.org/dataoecd/11/41/34428351.pdf

Raffer, Kunibert and Hans W. Singer (1996) The Foreign Aid Business. London: Edward Elgar.

Robbins, Stephen P. (2002) Organizational Behavior. London: Prentice Hall.

Samuel, Otto, Natalia Agopitova and Joy Behrens, Joy. (2009). Capacity Development Results Framework. Washington: World Bank Institute.

Schachter, Mark (2000) Capacity Building: A New Way of Doing Business for Development Assistance Organizations. Ottawa: Ottawa Institute on Governance.

Seidman, Ann and Nalin Abeyesekere (2000) Legislative Drafting for Democratic Social Change: A Manual for Drafters. London: Kluwer Law International.

Stiftung Bertelsmann (2006) 'Bertelsmann Transformation Index: Political Management in International Comparison', URL (consulted 17 June 2015): 
http://www.bertelsmann-transformation-

index.de/fileadmin/pdf/BTI_2006_Brosch_re_GB.pdf

Todd, Landman. (2006) Indicators for Human Rights Based Approaches to Development in UNDP Programming: A Users' Guide. New York and Oslo: United Nations Development Programme. URL (consulted 17 June 2015): http://www.undp.org/oslocentre/

USAID (1998) Handbook of Democracy and Governance Program Indicators. Washington, D.C.: Center for Democracy and Governance.

Vanhanen, Tatu (2000) 'A new dataset for measuring democracy', 1810-1998', Journal of Peace Research 37(2):251-265.

World Bank (2000) Reforming Public Institutions and Strengthening Governance. Washington, D.C.: The World Bank Publishin

World Bank (2001) Committee of Donor Agencies for Small Enterprise Development, Business Development Services for Small Enterprises: Guiding Principles for Donor Intervention.

World Bank (2005) Capacity Building in Africa: An Independent Evaluation Group Evaluation of World Bank Support. Washington D.C: World Bank. 


\section{APPENDIX}

\section{Section I: Principles of "capacity building"}

Two long-standing definitions offered by two major international donor organizations, UNDP and the European Commission, dating back 10 to 20 years, touch on what are essentially five key elements for capacity building in working with foreign governments and civil society in development. These key elements are highlighted in the text with numbers, with the first three relating to the three critical levels at which capacity building interventions must operate and the fourth referring to a principle of good governance. Indeed, they come out of the development literature going back at least thirty years (Honadle, 1981).

UNDP (1991) defined 'capacity building' as:

1) the creation of an enabling environment with appropriate policy and legal frameworks,

2) institutional development, including community participation (of women in particular),

3) human resources development and strengthening of managerial systems.

4) UNDP recognizes that capacity building is a long-term, continuing process, in which all stakeholders participate (ministries, local authorities, nongovernmental organizations and water user groups, professional associations, academics and others).

The European Commission definition highlights these four areas with a particular emphasis on the aspects of accountability to the public (the fourth category above): 'To develop and strengthen structures, institutions and procedures that help to ensure: transparent and accountable governance in all public institutions; improve capacity to analyze, plan, formulate and implement policies in economic, social, environmental, research, science and technology fields; and in critical areas such as international negotiation.' (World Bank, 2005:26).

Several documents of major international donor organizations have elaborated on these four areas, above, in documents that are readily available and repeated in multiple UNDP, World Bank, and other sources, including even Wikipedia's page for 'capacity development.' The wording is sometimes a bit different, but the concepts are the same. To help make the jargon for the three different levels of organizational performance intelligible, the terms can be clustered as follows.

- The 'enabling environment' - the legal and political authority, resources and incentives, for an organization to fulfill its legal, public, established purpose - is sometimes referred to as the 'institutional capacity' (slightly confusing it with 'institutional development') to denote the "rules of the game"; the legal or cultural environment in which organizations are constrained and directed (World Bank, 2005). The UNDP refers to this as the "broader system/societal level' or 'systems level' (UNDP, 1998). Added to legal and regulatory framework and policy concerns are issues of resources, management, and accountability. Major donors do not often use the word "culture" (sometimes they use the euphemism, "social capital" to assume that all societies are on a single path to development and simply lack certain aspects), but of course the cultural fit of a particular institutional function is a necessary part of an analysis of a sustainable system in the development context and is part of a complete analysis of the operating environment.

- "Institutional development" for effective and efficient management is sometimes defined as 'organizational development' or 'organizational capacity' (World Bank, 2005) with 'institution' referring to the overall political or government system as an institution and parts within it or alongside it (private 
businesses or community based organizations) as the 'organizations' or 'entities' (UNDP, 1998). The capacity building work here is that applied regularly in the business and community based organization (CBO) sectors to improve efficiency and performance through strategic planning and improvement of mission as well as building institutional resources and applying effective financial and organizational management, staffing, accounting and control, including the quality of feedback and evaluation systems.

- "Human resources" (skills) is sometimes referred to as 'human capacity' (World Bank, 2005:27). The UNDP also refers to this as the 'group of people level/individual development' (UNDP, 1998). Sometimes 'education and training' is also further elaborated as skills, information and perspectives (three sub-areas) that can all be objectively tested and tied to performance.

- In addition to the three levels above and accountability to the public, most definitions implicitly offer a fifth category; that of the long term sustainability of the capacity to perform the necessary function and the ability to attract resources to assure that sustainability. A UNDP definition made it clear that capacity was part of a:

5) 'continuing process' whereby individuals or organizations units perform functions 'sustainably' as well as effectively and efficiently (UNDP, 1998:10).

Others reiterate this as 'the attraction, management and absorption of resources' (Honadle, 1981) or as an 'ongoing and sustainable fashion' (Elton Consulting, 2002) or with the flexibility to deal continually with a changing environment.

There is also an understanding that these five elements must all be taken together. The UNDP makes clear that, 'Capacity building should be seen as a comprehensive methodology aiming to provide a sustainable outcome through assessing and addressing a whole range of relevant issues and their interrelationships' with none of these areas to be viewed alone (UNDP 1998). These elements and their relationship are presented in the chart below. 
Figure: The Five Key Principles of Capacity Building

\section{Organizational Function:}

$\underline{3 \text { levels of capacity }}$
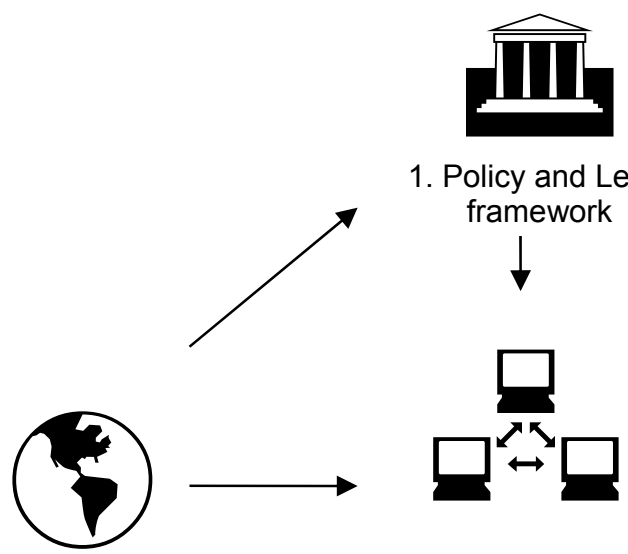

1. Policy and Legal framework
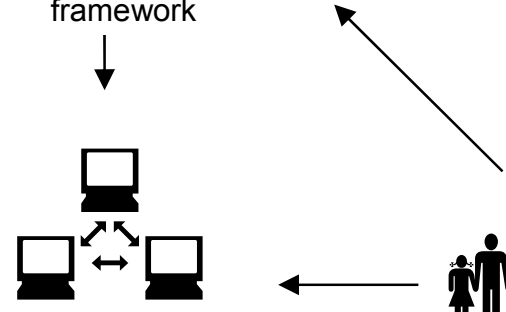

5. Sustainability

2. Institutional

Development/ Management efficiency
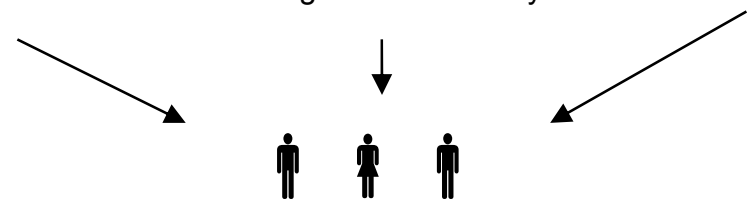

3. Human capacity

In conducting capacity building with non-profit organizations, consulting firms like McKinsey have introduced other frameworks that highlight concerns using different words but essentially reiterate the three 'systems levels' along with other elements like 'culture,' 'strategy,' 'aspirations' (mission and vision) and 'organizational management' that are already included components of the framework above (McKinsey, 2001).

That, in itself, is the basic standard of the tool. Like any tool, it also must be part of an established set of routine procedures for development interventions. There are a variety of studies of capacity building by donors that simply put them within the context of ordinary procedures for results based management, appropriate measures of the problems to be solved, the root causes of the problems, use of logframes to match interventions to steps in the root causes of problems, and use of standard cost-benefit analysis procedures and baselines to assure efficient use of resources to achieve measurable results promoting appropriate development objectives (Boesen and Therkildsen (Danida), 2004; Boesen, Christensen and Therkildsen, 2002). This is also essentially what the World Bank evaluations and various UNDP evaluations refer to when they fault their organizations for not applying the standard procedures of the field to these particular tools (UNDP, 1998, 2002, 2004; World Bank, 2000, 2005; Acharya and Wright, 2000; Linnell, 2003).

As evaluators have noted, there is nothing magical about capacity building. It simply requires following standard technical practices that are well established in the fields of public administration, law, general business management (strategic planning, personnel management, accounting for managerial control). These are basic textbook skills. 
There is certainly room for difference on achieving higher quality or applying new techniques for better results, as in all specialized and technical fields. But the key criticisms that have been launched in this field are not over the use of innovative new practices. They are simply about whether the most basic standards are being applied. And these can very easily be stated, referenced in standard texts, and put into an indicator to see whether they are being followed.

Just as in medical practice, a standard diagnosis requires certain tests, adherence to certain standards of cleanliness, patient ethics and care, and drug protocols, the basic test of competence is whether these are all followed. Once the basics are adhered to for licensing purposes, then there can be disagreements about new tests and procedures and their value. At this stage with "capacity building," however, we are still at the basic stages simply of establishing whether practitioners meet the basic "licensing" standards for establishing minimal competence.

Given that organizations have already defined the goals and purposes of capacity building and given that the procedures for design and evaluation of development interventions is also routine, it is relatively simple to run through a checklist to determine whether all of these elements are actually being followed or not in any specific project intervention and for holding development actors accountable. So why has no one sought to, or been able to do it?

\section{Section II: Indicators in the field and the lack of an indicator for "capacity development" interventions}

Practitioners have sought to create measurements for what is most difficult and what is fraught with political and disciplinary issues, but they have yet to offer a measurement in the area where there is already political and professional agreement; over whether their own activities comply with legal and professional standards; something that can be determined with a simple checklist.

Political scientists and development organizations have created a series of indicators to measure whether countries as a whole have the attributes of "good governance" that industrialized donor nations (politically) determine reflect the appropriate standard. These generally seek to measure the quality of governance in their entirety and in the aggregate, but without looking at whether specific projects actually improve governance and meet international standards (defined in United Nations treaties) for sustainably protecting cultural or community assets. For example, the World Bank's devised indicator uses a definition of governance that reflects its own goals of effectively managing the loans it gives to government officials to ensure that the Bank's objectives are adhered to. The indicator aggregates subjective views on 'voice and accountability, political stability, government effectiveness, regulatory quality, rule of law and control of corruption' (Kaufmann, Kraay, Mastruzzi, 1997). Similarly, Freedom House, a U.S. government funded organization, measures whether certain processes meet their subjective standards in seven areas: (electoral process; civil society; independent media; national democratic governance; local democratic governance; judicial framework and independence; and corruption) and scores whether a country is 'democratic' according to its own cultural preferences, rather than whether governance is effective in meeting local needs or even if it is in keeping with international law. A country could score well on this index but still destroy all of its minorities or sell all of its resources in violation of international treaties (Freedom House, 2006).)

A number of other indicators that are used in political science data sets do not seem to be used at all by development organizations and do not have direct applicability to measuring the quality of capacity building. These indicators rank countries (Polity IV; Marshall et al, 2006), pick specific attributes (Polyarchy 1.2 that measures 'competitiveness and political participation' (Vanhanen, 2000); 
generates an 'index of democracy' based on five categories (used by The Economist magazine, Kekic, 2007)) or substitutes goals of economic transformation that are in direct contradiction to the fundamental principles of good governance that require protecting assets and promoting sustainability (Bertelsmann Transformation Index in Stiftung Bertelsmann, 2006).

Though one might expect practitioners to have clear and simple indicators to support and justify program spending, the reality is that the development bureaucracies seem to be even more confused (or politicized) in setting the goals of governance and capacity building interventions than political scientists and in agreeing on what to measure.

Among development organizations, the one that has come closest to developing an indicator for 'capacity building' is the U.S. Agency for International Development (USAID). USAID's failure in this area, however, is that it does not start with a basic indicator for 'capacity building' or governance initiatives but tries instead to define every kind of outcome or outcome measure they would like to see for specific interventions. In other words, they substitute individual trees for the goal of protecting a forest. For example, USAID's measure of effective capacity building in the training of officials is whether or not it leads to 'Elected officials who have been trained' (a restatement of the input), 'and who say that they are using their new skills on the job' with 'examples of how they are using it' (USAID, 1988, page 166). Indeed, as an effective measure, this one violates the basic principles of governance since it turns an input (training) into the measured output and offers only subjective reports from stakeholders with no objective measures of improved performance to citizen beneficiaries. This is more an example of what is wrong than an attempt to provide measures. Though USAID also mentions that it would be useful to measure the 'skill level' of 'salaried staff,' this also has no relation to performances and outcomes. To put it more bluntly, the increased efficiency of an authoritarian or fascist regime in its executions, due to higher skill level, would receive high marks on a USAID indicator. So would simple bribes to government officials or indoctrination that was disguised as 'training.' A more recent document on 'USAID's Approach to Monitoring Capacity Building Activities' simply offers some formulaic suggestions such as: 'Avoid broad statements,' 'Be inclusive' and 'Be selective' (Muller, 2007). A USAID review of recent indicators showed little in the way of other approaches (Measure, 1999).

Rather than offer indicators, most development organizations simply offer checklists of ideas to consider when doing "capacity building." These can more easily be described as a set of cookbook recipes than as a legal means of applying standards of accountability. Organizations offering this "recipe" approach are the World Bank and Asian Development Bank (Ogiogio, 2005; Otoo et al, 2009), the U. N. system (that also offers national surveys of public perceptions rather than any objective professional standards, Landman, 2006; UNDP 2004), and the European Union (EC, 2002; 2001; EC undated, pre-2003). In many of these documents the definitions are circular and the goals become 'partnerships' and 'policy' improvement without any measurable content.

Among the most recent of these, one published by the World Bank Institute, there is still confusion between the tool of "capacity building" and any kind of development intervention, as well as between the content delivered and the form of delivery. The 'Capacity Development Results Framework' is described as doing everything that development does - 'design, implementation, monitoring, management, and evaluation of development projects' - in ways that are so broad as to make it useless (Otoo et al, 2009). Such 'frameworks' do not start with analysis of the problem, with problem trees, as a diagnostic for lack of capacity but seek to cover everything, including country-wide programme cycles, 'national development strategies, 5-year plans, and visions for the future' (Otoo et al, 2009:11). Essentially, in place of examination of capacity building, they have 
substituted frameworks for how to create logical frameworks for any kind of development intervention through any kind of modality.

Moreover, most of the "framework" (rather than "measurement") literature comes from publications of the donors, themselves, with little outside to create accountability. Indeed, there still does not appear to be even one international journal devoted to "capacity building" anywhere. The result is that the real problems in the field, of hidden agendas for corruption and dependency, are never examined other than in vague euphemisms to protect those responsible, using bureaucratic jargon like 'unintended negative consequences' and lack of 'clarity of mission' or lack of 'supportiveness of stakeholders' among a long list of 'capacity factors' (Otoo et al, 2009:12). At best, the focus is only on 'educational impact analysis'. The problems remain hidden, by design.

Similarly, a number of diagnostics have been developed in the actual practice of "capacity building," mostly with community based organizations (McKinsey, 2001; Christensen et. al., undated; Gubbels and Koss, 2000; Lusthaus et al, 2002). Mostly these parallel and actualize approaches that in the business literature would be called 'strategic management' or 'accounting for management control' (Emmanuel, Merchant and Otley, 1990). However, they have yet to be applied as accountability tools to the billions of dollars in international interventions.

It is ironic that while there are two recent international treaties that guide international interventions and reference the idea of standards - the Paris Declaration on Aid Effectiveness (2005) and the Accra Agenda for Action (2008) ${ }^{44}$, now followed and reinforced by the International Aid Transparency Initiative signed in Busan (2011) - they offer few specifics and little enforcement, thus reflecting the exact problems they claim they are trying to solve.

With so much effort to develop "indicators," the fact that none of them seem to do what is so simple seems to suggest how deeply rooted are the cultural and institutional barriers to holding even governments in Western "democracies" accountable for billions of dollars of public spending.

\section{Section III: The problem with many "capacity building" projects and the real value of an indicator}

The World Bank and other organizations' evaluations readily admit the problems of current capacity building approaches, though they do so euphemistically. It is easy to take their own words and to expose what is going on in simpler language. What the donors' own internal critics have exposed is that project fail because donors want them to fail to protect other agendas and because major international organizations are using "capacity building" as a cover to bribe or co-opt officials for foreign agendas. One World Bank study admitted both the goals and the mechanisms of how this works, noting that 'governments generally are inclined to improve services demanded by powerful interests' and then noting specifically that it is 'donors' payments' that 'subordinate the coherence of the machinery of government to the narrower goal [and] short term gains ... of project implementation' for the donors (World Bank, 2000:41).

The mechanisms are also clear. Often the corruption that foreign donors claim they are seeking to stop are actually initiated or reinforced by donors themselves, with "capacity building" one of the ways of buying off of government officials directly through what the World Bank itself admits are 'donors' payments of salary supplements' (i.e., what could be seen as the equivalent of illegal bribes under the

\footnotetext{
44 Accra Agenda for Action (2008) URL (consulted 17 June 2015): http://siteresources.worldbank.org/ACCRAEXT/Resources/4700790-1217425866038/ACCRA_4_ SEPTEMBER_FINAL_16h00.pdf.
} 
U.N. Declaration Against Corruption and Bribery ${ }^{45}$ ), in addition to 'grants and concessional loans' to 'encourage line ministries ... to "market" to donors' (World Bank, 2000:41). The World Bank notes that the approach is usually to exclude the public, 'interacting exclusively with government interlocutors' while disguising bribes in the form of 'computers and other inputs' where it is obvious that no changes in services will occur because of 'the absence of deep and sustainable demand for institutional reform.' Moreover, they note that, 'This applies to much of the donor community' (World Bank, 2000:14). Indeed, this reinforces what the previous indicators designed by this author to test foreign projects for 'dependency/colonialism,' 'sustainability,' and 'democracy' helped reveal; that many of the large donors are in fact continuing to pursue a colonial agenda with little oversight or accountability and the creation of tools that hide their underlying intent (Lempert, 2009a, 2011; Lempert and Nguyen, 2008).

Most often the Ministries or government organizations to be 'built' (what many observers would view as a euphemism for co-opted with foreign gifts, funds and advisors) are the Ministry of Planning and Investment, to serve as a (dependent or 'colonial') intermediary of international investment banks (Mayo, 2009), the Judiciary in order to protect international businesses; the Parliament in order to write the laws that open their economies and systems to foreign businesses and other influences and then to promote these changes to the public; the head Ministers in order to write the development plans and policies and claim they are domestic aspirations rather than foreign driven; Ministry of Health to stop contagious diseases from leaving the country, etc. The goal in building capacity in the non-governmental sector is often to generate business joint ventures to the benefit of foreign business, to influence current and emerging leaders of political parties while improving their ability to manipulate their citizenry to support foreign agendas, and to build a foreign funded rather than locally accountable or sustainable civil society to lobby for foreign interests (generally for foreign investment; often for 'women's rights' as a way to destroy traditional practices and free women for work in export processing zones or as administrators for the foreign sector) (Lempert, 2009a, 2012). In the author's experience over 30 years, in almost all of these projects, the public is excluded by design and "accountability" is really accountability to the agenda of the donors, not of any parts of government to citizen oversight, and the amount of secrecy has actually been increasing with consultants forced to sign statements of confidentiality that the author, as a lawyer, believes to be in direct violation of most public transparency laws (Lempert, 2009b). As the World Bank itself noted, the public 'voice' is systematically excluded (World Bank, 2000:43).

The fact that this happens is an open secret with little or no influence either from the taxpayer/donor public or from the publics in countries where the projects are being run. In fact, most international development organizations have now established secrecy clauses (in violation of public laws in both donor and recipient countries) to hide information about these projects under the pretext that officials in recipient countries would not candidly discuss their capacity "needs" if they believed the public might learn of their incompetence and fallibility. Some vignettes taken from some actual projects in which the author is familiar (in the section below) highlight the absurdities and flagrant abuses that now occur. In presenting these cases, the author draws on professional experience and participant observer methodologies used in the field of social anthropology as well as determinations applying methodologies of law and public administration.

The mechanisms that cloak these bribes as "capacity building" are relatively transparent and are easy to reveal with a good indicator that exposes lack of

45 U.N. Declaration against Corruption and Bribery in International Commercial Transactions (1996): A/RES/51/191. URL (consulted 17 June 2015): http://www.un.org/documents/ga/res/51/a51r191.htm 
safeguards against conflicts of interest of donors themselves, and of recipient government "stakeholders" and the lack of transparency has nothing to do with encouraging reform and everything to do with covering up the abuses. The extent of these abuses now appears so widespread that most professionals in development can easily list the forms of what could best be described as "shadow bribes" take without a moment's hesitation. This author has personally witnessed them delivered, in violation of local and international laws, by almost every donor organization in the form of attendance fees to government officials for simply coming to donor workshops (listed as "per diems" or envelope money) so that donors can then seek and spend more money on the pretext that officials are eager for such training and that they have an impact, "study tours" that are disguised junkets, as well as hotel buffets and entertainment (usually in lavish Western settings) in recipient countries. Officials are also easily bought in the name of capacity building; with donor organizations working in fact as tour agents and caterers, running parties, giving away branded items with logos (including umbrellas, travel bags, and briefcases). Institutions like the UN appear to have been turned into lobbying agencies or missionaries, for hire by the larger donors who pay them to use government contacts to promote specific agendas of the international banks or of economic blocs seeking to expand their influence in trade agreements or "harmonization" of laws, convincing national officials to legislate and adopt such policies and to claim that it is their local people who have demanded them.

Many other projects appear to be simply naïve, throwing money at symptoms of incompetence and inefficiency with no idea how organizations work, what the incentives are of individuals within them, or what they are even supposed to do in a functioning and sustainable system and this is a result both of the hiring of staff with few skills (other than language) and little adherence to codes of professional responsibility, with almost no outside direct public oversight. Project approval procedures have largely been corroded in order to facilitate (what can be described as "corrupt") agendas for purchasing government systems that keep money flowing, many projects are implemented with no standard procedures to follow.

As a more recent World Bank review of 'capacity building' projects admitted, most such projects 'do not specify the capacity building objectives,' lack 'adequate needs assessments' and do not even consider 'processes of organizational and behavioural change' (Ogiogio, 2005). Thus, large numbers of projects come to be funded where the goal of "training officials" is about as effective and well thought out as schemes teaching elephants to fly. Officials who lack the salary, the ideology, the incentives or the capacity will not produce services no matter how much education they have. In other cases, government systems that are riddled with nepotism or politics, receive capacity building funds that essentially seek to turn secretaries into brain surgeons without recognizing that the processes of recruitment that are politicized and corrupted and are the source of the problem. Rather than improve organizations, foreign funds allocated for "capacity building" are often propping up former generals and their children in regimes that are largely recognized as corrupt (by Transparency International and other organizations measuring accountability) in order to keep them employed and in power; building the "capacity" of dictatorships to maintain their rule. "Awareness raising" projects for "accountability" and "combating of corruption" often throw training at the very people who are the perpetrators of the crimes and as effective and well thought out as schemes trying to turn wolves into herbivores.

The donor justification is that transferring funds to government officials to help "demonstrate" how to run fair judicial systems or equitable public services, can help convince them to "buy in" to the idea. Yet, without any pressures or conditions to pressure them to do that or convince them why it might be in their interest to do so, the approach is akin to believing that giving money to criminals for charity will turn them into humanitarians rather than simply end up in their foreign bank accounts. 
Other projects offer remedial education to specialists or adults when the real failures have occurred in the basic education system, in professional schools, or in selection procedures. A lack of proper analysis of the sources of the problem again results in treating symptoms rather than the disease.

The irony of "capacity building" is that the organizations claiming to be the experts are often the last to have their own internal experts who have read the basic textbooks in the field at the university or masters level. Few seem to follow the basics of development project design and "results-based management" (with standard practices like problem trees, root cause analysis, appropriate identification of inputs-outputs-outcomes, and use of baselines, and cost benefit analysis) or who even apply their own international treaty agreements and mission statements in areas of sustainable development and protection of cultural rights and diversity (rather than promotion of industrialization, consumption and economic exploitation) (Lempert, 2014).

There is nothing here that cannot be improved simply by holding donor organizations to safeguards against conflicts of interest and to textbook principles. A list of some of the standard textbooks that apply to capacity building in this field would include those of overall systems and system change (Forrester, 1994), principles of legal drafting for democracy and efficacy (Seidman and Abeyesekere, 2000), understanding of human cultural differentiation and sustainability (Ember, 2006), basic business analysis and organizational strategy for effective management control (Garrison, Noreen and Brewer, 2005), principles of public finance (Musgrave, 1973), organizational behaviour (Robbins, 2002; Nelson and Quick, 2005), personnel management (Noe, Gerhart, Wright and Hollenback, 2007; Dresang, 2009), training and education theories to differentiate skills, perspectives, and information (Lempert et. al., 1995), and current models of promoting competitive business development services (World Bank, 2001). Others might be added in the areas of appropriate roles of NGOs (innovation and advocacy) versus government (services), and mechanisms for accountability and avoiding conflicts of interest. The point is simply that the disciplines and approaches are well established but many donors seem not to even know their own profession; perhaps deliberately.

\section{Vignettes: what really happens in "capacity building" projects}

Some standard project types and how they are rigged or doomed to "fail" from the start are described below.

\section{Projects to turn wolves into doves}

International projects work with all three branches of foreign governments in approaches that seemed designed to keep the wrongdoers in power by assuring that only they have the "expertise" to run government (in ways acceptable to the donor). While projects with Ministries seek to improve them through proselytizing rights treaties to the very people who are the abusers and who have no incentive to change, the classic examples of capacity building failures are those that work with the legislative and judicial branches of governments in developing countries. The responsibilities of these political institutions are to represent the public will in ways that balance interests of different cultures (to assure their sustainability) and of individual rights and preferences, through legislation (legislatures) and through fair and representative means of resolving disputes (adjudication). The "capacity" they need is the capacity to protect and reflect these interests in the process of legislation/policy and in conflict resolution among different interests. That is not what foreign projects seek to promote. What they do, instead, is the following in three basic types that this author has worked on directly.

- UNDP Parliamentary Capacity Building Projects with donor support "Parliamentary Capacity Building" projects are run almost everywhere, with 
funding from almost every major donor. Those that the author has seen in several regions show no intent to address the real failings and capacity needs of national or local legislatures.

If parliaments are failing, it usually means that democracy itself is missing since this is the real capacity underlying a legislature: the public is badly represented, unable to control its representatives, unable to understand what legislation is and how to offer it, and/or that the legislature itself is a symbolic puppet (a legacy of colonial rule) that has no real power to challenge military, police, or economic (domestic or foreign power). It may mean that the legislature is simply a ritual body with no real direct control of most government spending (that may come from overseas governments rather than from taxes or from elite control over some resource that generates funds). In a functioning parliament, the public sets the agenda for sustainable development, the courts assure that the legislature upholds international treaty goals for sustainable development, and competence of parliament is assured through the power of parliament to increase its funding through taxes and to hire the best people to carry out its tasks. Failed officials are voted out of power and their failed staffs go with them.

What happens in these projects, however, is that the foreign donors seek to reinforce the idea of permanent, "efficient" and "expert" parliamentary staff alongside career Parliamentarians who remain no matter what election results say, with training in foreign languages and in passing of foreign laws favoured by the donors. Training includes instruction to elected deputies on how to appear democratic by meeting (often for the first time) with their constituents to show how "democratic" they are. The projects promote connections with foreign parliaments in donor countries as a way to create a brotherhood among these elites and in ways that reinforce dependency for future favours.

- World Bank Ministry of Justice projects to promote "rule of law" - While these projects in "efficiency" of "administration of justice" are most often supported by the World Bank, they are copied by other major donors.

As with parliaments, if judiciaries fail, the capacity problem is almost always in their democratic legitimacy rather than in their inability to efficiently or expertly administer (in)justice. Where judiciaries fail, it usually means that the public is not represented as jurors or in democratic oversight and balance of judges, that citizens lack the power to enforce norms on military, police, or domestic and international economic powers, and that the public and judges lack the funding to be educated and involved in complex decisions. Working judiciaries use the law to bring in the funding and expertise they need, with public support, to challenge abuses of power and imbalances in representation.

What happens in these projects is that rather than focus on "justice" and equity, donors seek to reinforce the idea of permanent, "efficient" and "expert" elite selected judges who are "independent" of the public but still vulnerable to existing economic and military power. Support for "capacity" includes study tours, computers and training of judges. Projects for legal "access" mostly seek to assure that the legal order is efficiently enforced on individuals in minor matters and that edicts are known to the population rather than subject to change.

On one Japanese funded project that the author worked on for the World Bank in a country described as having no rule of law and where project funding was slowed due to violation of Bank regulations against insider dealing of Bank funds (detailed in World Bank documents), a Ministry of Justice not only gave an ultimatum that the author steer loan funds to a committee of their friends to allocate funds for study tours and computers, but they also demanded a kickback from my salary to the Ministry. The author's approach was to offer loans to students and to promote lawyers representing citizens, farmers and workers to benefit small business and sustainable development, rather than to just promote business law and extraction of that country's resources (oil). After more than 15 years, the World Bank 
continues to support the wrongdoing (and the same ruler and legal system remain, with the country increasing their oil contracts).

- Major Donor Projects on "Human Rights" and "Anti-Corruption" with Ministry Officials - In many fields, capacity building has developed as part of an "industry" by certain donors to propagate certain treaties or moral values on the pretext that such proselytizing solves problems. Donors rushing to offer support given on the size of the perceived problem (violations of rights or corruption).

In most cases, the real problem is that Ministry officials have no real power or incentives to confront wrongdoing and the public (and communities) are too weak to protect and enforce their own established rights traditions (in many cases, traditions that were at times more progressive than those of developed countries but that were and continue to be destroyed by colonialism and globalization).

What happens on these projects is that rather than describe the power imbalances or the reasons why cultural systems that protected rights were destroyed, the projects focus on these government officials who are either powerless, indifferent, or the source of the problem; identifying them as "duty bearers" rather than as oppressors or spectators. The approach is purely symbolic and fits the definition of a public relations 'whitewash' or 'rights wash' (Lempert, 2011).

Typical projects are those offering "human rights training" for police and prison guards who themselves may have been victims of violence or who are trained in violence and lack the capacity to use other approaches. Similar are courses in "anti-corruption" for military or officials who are simultaneously being purchased by foreign donors or pressured and bought by foreign governments and corporations. Most of what is really learned, as the author has observed by analyzing the curriculum and measuring the impacts, is how to mouth slogans and falsify international reporting on compliance. The effect is to undermine real public pressures for change by demonstrating the networks that the abusers have now established with international authorities. Meanwhile, those who attend project workshops not only benefit from the disguised bribes of free trips and buffets and per diems, but they also walk away with everything from logo blazoned umbrellas (a UNDP "anti-discrimination" project that the author evaluated in a formerly Eastern Bloc country, that actually taught officials how to destroy cultural differences and force everyone to the lowest common denominator as a familiar Stalinist example of non-discrimination) to "certificates" of course completion that are used as chits for study scholarships and job opportunities.

\section{Projects teaching elephants to fly like birds}

International projects not only work with governments but also with "civil society" including businesses and civil society organizations in claimed attempts to build capacity for "market economies" or for "democratic oversight." A typical failure in both the government and public sector is that they train their "partners" with the very skills that the organizations lack but in areas where the specific individuals will never have the ability to perform those skills. In developed countries, organizations hire people who have the ability to work as managers or fundraisers or advertisers or creative product designers to expand organizations, recognizing that people have different and specific abilities. But in the development community, where it is determined that organizations cannot fire poor performers or hire competence, the idea is that capacity can be built by turning health Ministry secretaries into brain surgeons, state lumber company managers into environmentalists, state coal company officials into computer software entrepreneurs, and military officials at national and local levels into legislative drafters for democratic participatory oversight laws. Examples of two common types of failures are the following.

- NGO Capacity Building to Promote Civil Society - Almost every donor now seeks to support "civil society" projects. What that usually means, in the 
author's experience evaluating projects in this sector, is throwing money at those organizations that have been created as dependent branches of foreign NGOs to oppose or perform the functions of governments in recipient countries, rather than to actually rise up as citizen funded representative organizations that act as monitors of government and business to assure their accountability. Since these organizations are established as administrative arms of foreigners that have no understanding of how to respond to citizens in their own country by offering them real benefits and asking for their funds, attempts to build their capacity and make them sustainable fall on deaf ears. Often what they really teach is the fundraising skills of how to keep appealing to foreigners for money. With little or no management ability, little or no ability to plan, and no understanding of the actual role of civil society, "capacity building" here in skills like management, strategic planning, or even higher skills of statistics and lobbying, is almost always the equivalent of the blind leading the blind.

- European Commission Network of Schools of Political Studies to Teach Tolerance and Rights - A typical capacity building project supported by various donors is on reaching out to young elites in developing countries in a purported attempt to train them in new concepts such as "democracy" as those countries are brought into the orbit of the donor. The European Commission, for example, in a project evaluated by this author, spent millions of Euro identifying young political elites (usually ruling Party members, on career tracks of political patronage) in former Soviet and Eastern European countries being brought into Europe, on the pretext of teaching them "human rights", "tolerance" and other European "democratic" values. In fact, what these projects appear to actually teach is how to conduct political discussions behind closed doors with political elites, including those of Europe, and how to maintain "networks" with each other through meetings in international hotels, rather than through meetings and accountability to their own publics. The Moscow branch of this school brought Henry Kissinger to Russia to explain to these identified future elites how he ran an unaccountable U.S. foreign policy under the Nixon Administration.

\section{Section IV: How some organizations do in "capacity building", scored using the proposed indicator}

Below are the results of use of the indicator offered in this article on several different categories of international capacity building interventions that are described in international development literature. Some of them are from the author's first hand experiences in more than 30 years in international and community development work. From the categories, it is clear how the scoring works to separate different types of projects in terms of quality as well as to expose hidden agendas and failures and to note where there is a need for accountability and improvement.

Note that even though not every question applies to every kind of project, the scoring is still designed to yield a scoring spread that leads to categorization and comparison and that also shows how some projects in a category can do better or worse depending on their attention to specific project features that are highlighted in the scoring system.

Before reading these results, consider the following. Most "self-rating" systems using indicators grossly over-inflate results because of the natural tendency to look uncritically at one's own projects (why there is a need for clear and objective grading standards) and because there is a tendency to avoid considering several organizations at once when rating those organizations one favours. Any rating instrument needs to be "calibrated"; i.e., tested for consistency using the same test question multiple times on multiple organizations in order to reveal differences. Each observer doing the test ultimately reaches some internal consistency after a 
number of tests, but different observers are likely to come up with different results because they are "harder" or "softer." The scores below are those consistent with the judgment of the author and they are an example of strict application of the ideas, such that weaknesses are revealed as areas where improvement is needed. If such a tool is ultimately adapted by professionals and subject to multiple tests, there would ultimately be a consensus on the scaling and the rating system.

The scoring below is not an "absolute" and there is not enough space in this article to present the full detail and evidence to fully explain the scoring for every organization. A sample of the process with full detail for one organization is provided in Appendix Section V. Here, the reader should view the scores as coming from a larger set of data and the professional judgments of the author in following standard social science disciplinary protocols.

Models of Comprehensive Capacity Building: 8-11 points. The examples that fall into this category are rare.

The Marshall Plan De-Nazification of (West) Germany after World War II - Though it is a bit of historical guess-work, probably the Allied reconstruction of Germany after World War II would earn 9 to 11 points, at the top of the scale. There was little danger of collusion with the Nazi officials since they were sentenced for war crimes, and the approach was to rebuild democracy and rule of law at all levels from the schools to the courts to the constitutional and political system. Given the understanding of sustainability in 1945, the approach fulfilled it (and tried to begin to rebuild cultures of minorities like Jews and Roma/Gypsies). Of course there was self-interest on the part of the U.S. and U.S. corporate and global interests (possibly losing a point on Question 10), though the U.S. also understood the long term future interest of a sustainable Germany and built a country that competed with the U.S. economically. There are also questions as to whether the U.S. military and government that were implementing this aid were really subject to clear accountability to the U.S. public (though possibly more so then than today!). This is a model intervention, but it also occurred under rare and specific circumstances. For comparison, you can compare the "de-capacitization" that occurred in East Germany under the Soviets.

"Street Law" Civic Education Projects, "Where There is No Doctor" Training of Basic Primary Health Care, Grameen Bank Community Self-Financed Lending, "Manage Your Own Business" Training for Family and Household Businesses (GTZ and other donors), and Small Scale Participatory User-Group Projects (such as AFAP's Local Contributory Irrigation Projects - The common dimension of these projects is that they start with a basic need (legal skills, health skills, business and lending skills) and work directly with community groups to build those skills and to change cultures at grassroots levels. In doing so, they can earn about 8 points. These NGO projects are all examples of competence in capacity building in specific fields, building sector and governance skills and institutionalizing them, where major donors fail. The weaknesses that these organizations share is that they do not consider the overall sustainable development impact of their interventions that could be negative (Question 1) and they don't look at the larger systems that have failed to seek ways to get to the real root causes of the problem (Question 3). However, they score well in other areas. There are no conflicts of interest in their work but they potentially distort existing service systems (Question 18).

Minimally Competent Approach to Capacity Building: 4-7 points. Examples here are of interventions that are technically competent but that may be largely flawed from a development perspective as destructive of local cultures.

British Establishment of Public Administration Schools in Colonial Africa in 1950 as Part of State-Building; French Support for Public Health Systems (Hospitals, "Pasteur" and other Institutes) in Colonial Africa and Indochina - The "positive" aspects of the European colonial legacy are the institutions that have carried over 
in those countries in the post-colonial period and both of these interventions score about 4-5 points. The areas in which they are deficient are clear: the goal was not to promote sustainable development of the natives but to "civilize" them in ways that destroyed their cultures and "modernized" them to follow European approaches. Systems were not "fixed" but destroyed. So there are no points on Questions 1 or 8 , and colonial regimes are not models of accountability (Question 10), but these projects score 7 of the 11 positive points. These colonial interventions obviously created and empowered local elites (Questions 13 and 16) and there were conflicts of interest on the parts of the colonial implementers (Question 15), for a loss of about 3 points.

Narrow or Weak Intervention: $0-3$ points. Projects that are technically competent and that offer public training through market solutions can also score points on competency but fail if they are promoting a particular agenda that is not sustainable development and that could distort overall government functions.

Agricultural Extension projects of major donors and Small Business Promotion Projects (of donors like the World Bank's International Finance Corporation/Mekong Project Development Facility in Southeast Asia) -- These projects can earn between 2 to 6 points, depending on how carefully they actually promote a "business development services" approach that builds private sector capacity, rather than seeks to replace it. Among specific skills promotion projects that work widely with the public on training and outreach and that offer fee based courses or services, these approaches are technically competent in the very basics of capacity building. The reason they only earn about 4 points of the first 7 is that they do not consider overall development (they start with an ideology of productivity) and do not effectively measure the overall function of learning and applying information (about business or agriculture). The organizations running these projects are not accountable and the approaches they promote are sometimes sustainable and long-term but sometimes only short-term inputs. They may lose points for subsidizing elites or for failing to promote truly comprehensive and market based solutions.

Administration of Justice Projects, Judicial Training Projects, Human Rights Training for Police and Judges, projects of the World Bank, European Commission (EC), USAID, UNDP, and other donors - These projects, described in vignettes, sometimes show slight benefits in improving efficiency or in ameliorating symptoms, but they lose points by failing to focus on democracy and equity and by entrenching existing elites and their inequities, and at best score 3 points if they save public funds and address inefficiencies in spending and government action, though more often go slightly negative.

Incompetent Projects with Hidden Agendas that have been corrupted Either By the Donor Agency, Stakeholders in a Developing Country Bureaucracy, or Both: < 0 points. International organizations working in areas like "justice" and "antidiscrimination" and building "parliamentary" and "government" "capacity," claim to be doing much more than they really are and the test exposes them, quickly as promoting hidden agendas that undermine democracy rather than promote it, with scores of 0 to as low as minus 7 points $(-7)$.

United Nations Capital Development Fund (UNCDF) and other "Local Development" Projects supported in almost the same model by a large number of donors (e.g., the SEILA project in Cambodia with DFID, World Bank, and UNDP support, local governance projects of GTZ, SNV, Lux-Dev, and Belgian Development Assistance in Vietnam) - All of these projects work on a common model of transferring funds to local government officials to promote necessary "decentralization," with claims that they are simultaneously building local government "capacity" and supporting "participation/democracy" by asking some local citizens what gifts they would prefer from the foreign donors in a list of giveaways. A typical score for these projects is strongly negative (-4.5 points), 
suggesting that not only do they lack competence but that they are being used to manipulate local governments and destroy local systems for a colonial objective of the donor. The detailed analysis in the Appendix (Section V) of UNCDF demonstrates the conflicts of interest and the lack of professionalism built into the design of these approaches. These projects fail to examine what systems are broken from the perspective of local cultures and are used to promote agendas of globalization/export and industrialization that are favourable to donors and in violation of international treaty agreements.

School of the Americas (U.S. Military) and Other Military and Police Capacity Building Programs in Iraq and Elsewhere - As expected these projects to build "professionalism" may have good log frames and partly support the role of defence and security ( +1.5 points) but they do not look at root causes of instability and work to militarize conflicts, building systems that weaken citizen control over their militaries and elites, militarize conflicts, and are in the interests of the U.S. more than local citizens (-5 points), leading to a score of minus 3.5 points $(-3.5)$. They actually score slightly higher, ironically, than "local development" projects because they are strengthening a system, despite the negative effects of that system.

'Civil Society Promotion' Projects of the European Union (EU) and USAID in the Balkans and Elsewhere, Ashoka Foundation Civil Society Grants - The standard "civil society" promotion project of major donors transfers funds and builds skills of a select number of Western-style NGOs (rather than already existing community organizations of political, tribal, or religious identity) in ways that undermine their sustainability and seek to transform rather than repair local cultural mechanisms; earning minus 5 points $(-5)$. The roles of NGOs are defined as providing services that government should provide or lobbying for foreign concerns rather than aggregating local interests with local control and sustainable funding. The projects score no positive points because they do not examine local needs and do not build overall skills or functions, but pick organizations and partners to receive funds. Partners in developing countries who receive funds and counterparts who administer the projects introduce biases (loss of 3 points) and the projects actually weaken citizens relative to these foreign-funded organizations, while also distorting civil society and the appropriate role of government and civil society in services (loss of 2 points). Instead, these projects should start at the school level, teaching skills, and work with existing organizations that were weakened by colonial rule.

Standard UNDP, EU, and World Bank Capacity Building at the National Government Level with Parliaments, Planning and Investment Ministry, and Line Ministries - While these expensive projects should reflect the highest competence and the state of the art in procedures, the reality is that they are at the bottom of the scale, failing in almost every way, and scoring minus 7 points (-7). The indicator easily exposes them as indicative of an agenda that is designed to buy off foreign governments and to make them unaccountable to their publics in support of an external agenda, rather than to promote capacity in line with international law and basic principles of development. They score no positive points because they do not seek to balance sustainable systems, address existing problems, find what is broken and needs to be fixed, or promote necessary functions (such as "legislation" or "asset protection"). Instead of defining and measuring a problem, projects are targeted at specific government entities and justified on the basis of symptoms ("weak governance," "corruption") and the need for "governance" projects to "promote development" or "promote the Millennium Development Goals." There is no measure of output or outcome other than receipt of transfers of money and services that are then defined as "strengthened." Almost all potential conflicts of interest are present (loss of 4 points) and the ability of officials to influence the projects also promotes weakening of citizen powers and oversight and subsidization of country elites (further loss of 3 points). 


\title{
Section V: An example of applying the indicator: The United Nations Capital Development Fund
}

\author{
Scoring of United Nations Capital Development Fund (UNCDF) on the 20 \\ component questions of the indicator
}

\begin{tabular}{l}
\hline \\
\hline \\
UNCDF's \\
Organizational \\
Mission (Claim) and \\
Role of Capacity \\
Building according to \\
UNCDF website
\end{tabular}

Preliminary Information for Assessment

'The United Nations Capital Development Fund (UNCDF) offers a unique combination of

investment capital, capacity building and technical advisory services to promote microfinance and

local development in the Least Developed Countries (LDCs)'

Through its programmes, UNCDF strives to contribute to the attainment of the Millennium

Development Goals (MDGs) and to the implementation of the Brussels Programme of Action for

LDCs in a direct, concrete and measurable way.

There is growing consensus that democratic governance creates the conditions for sustainable

development and poverty reduction. Similarly, it is increasingly accepted that achieving the MDGs and eradicating poverty needs to be done at the local level and thus requires the involvement of local authorities.

UNCDF's local development programmes support national decentralization strategies in the LDCs and seek to improve social services, governance and pro-poor economic infrastructure at the local level by providing technical assistance and investment capital directly to local authorities. UNCDF's investment capital is flexible, high-risk and innovative. It is channeled primarily to poor rural areas in the LDCs where poverty reduction, capacity and governance challenges are typically the greatest.

Overview of Claimed Activities: UNCDF's Local Development Programmes (LDPs) introduce participatory planning and budgeting systems at the local level. These programmes seek to ensure a voice for women and other disadvantaged groups in local public decision-making. The programmes also work within, and support, the national system of central-local government institutional and fiscal relations.

Description of Actual Interventions:

UNCDF's "Capacity Building" Activities in practice, according to UNCDF website
- Emphasis on Local Level Institutional Development: Improving procedures and practices for local level resource mobilization and public expenditure management (including development planning, investment programming, performance budgeting, procurement, implementation, asset management and internal controls) to enhance the efficiency, effectiveness and accountability of local authorities in poverty reduction activities.

- Performance-linked block-grant funding facility: Providing local authorities with general purpose development budget support for sustainable, small-scale, local investments in social and economic infrastructure, such as schools, health clinics, rural roads, water and sanitation and natural resources management. This support is linked to agreed measures of local performance and serves as an incentive for local capacity building.

- Local Economic Development: This approach emphasizes the importance and leadership of local authorities in encouraging and supporting local entrepreneurship and local enterprise creation.

UNCDF has no clear mission statement and starts off its mission by defining its tools rather than its ends. It confuses several potential end goals that it offers as political slogans without definitions - sustainable development, the MDGs (that do not promote sustainable development if improperly applied), eradicating poverty, and local development - with means to those ends such as microfinance, governance, and decentralization. Rather than offer measurements of results, it justifies actions on the basis of politics and slogan of a "growing consensus" that has no clear link to beneficiaries or the public that funds the organization. The role of "capacity building" along with other tools like investment capital is equally confused, with the role of these tools in helping to achieve the means to an ends or the ends unclear. There seems to be a formulaic approach to building local government infrastructure for delivering grants to increase productivity, rather than supporting democratic accountability or sustainable development, or protecting communities or cultural groups. It looks like the organization is opportunistic rather than goal driven and this waves red flags for the use of "capacity building" as an appropriate development tool. UNCDF offers several slogans about how it is "participatory," builds local tax systems and other forms of "accountability" but none of this is demonstrated in operating procedures or design given that it simply funnels money and training to local officials without assessing the problems or building citizen skills. An organization that defines itself by shifting of money and resources (here simply "investment capital") and promoting "growth" without clear development ends is almost certain to score miserably on a development index that tests how it seeks to use a tool properly and professionally for development objectives. 


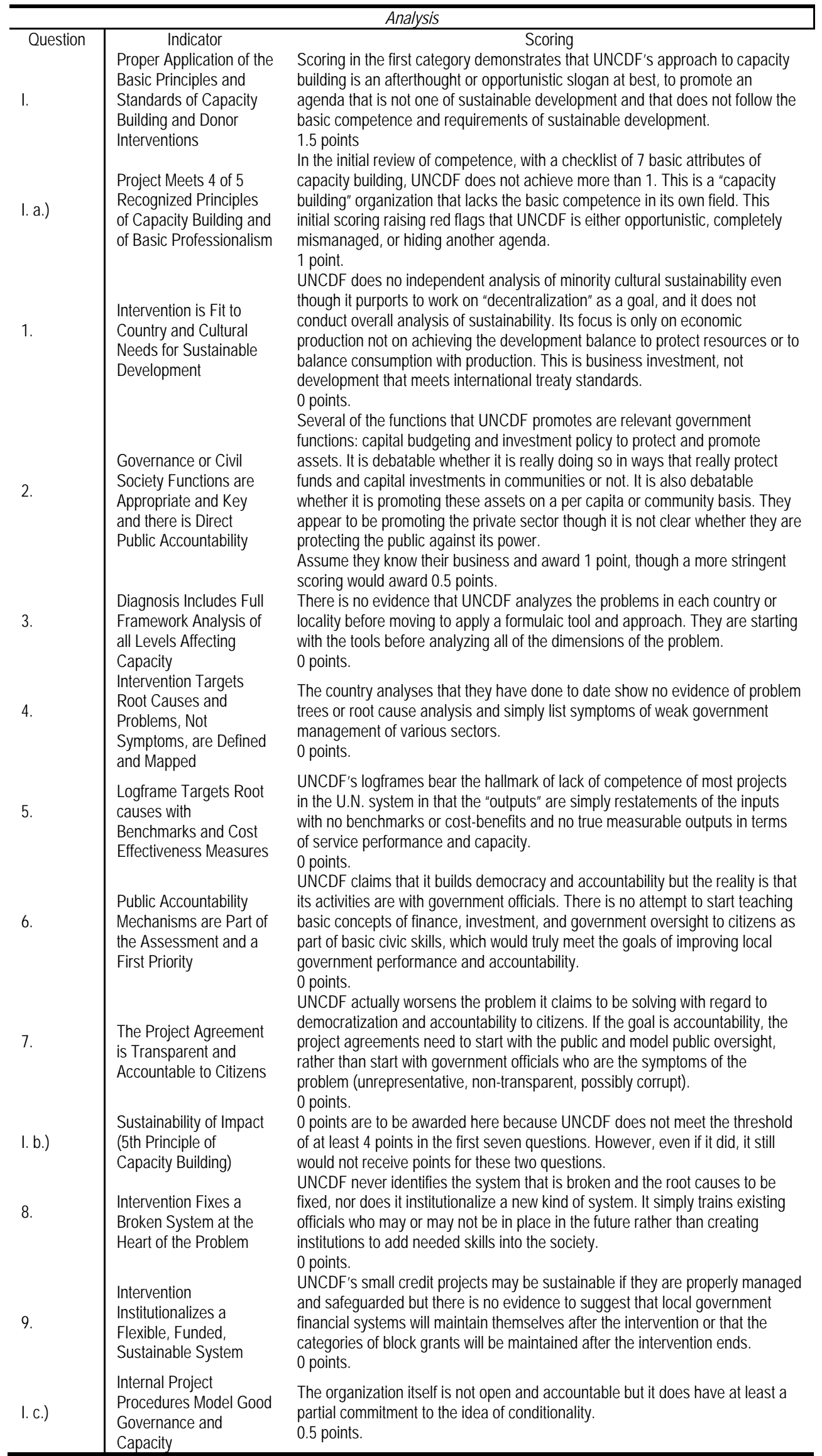




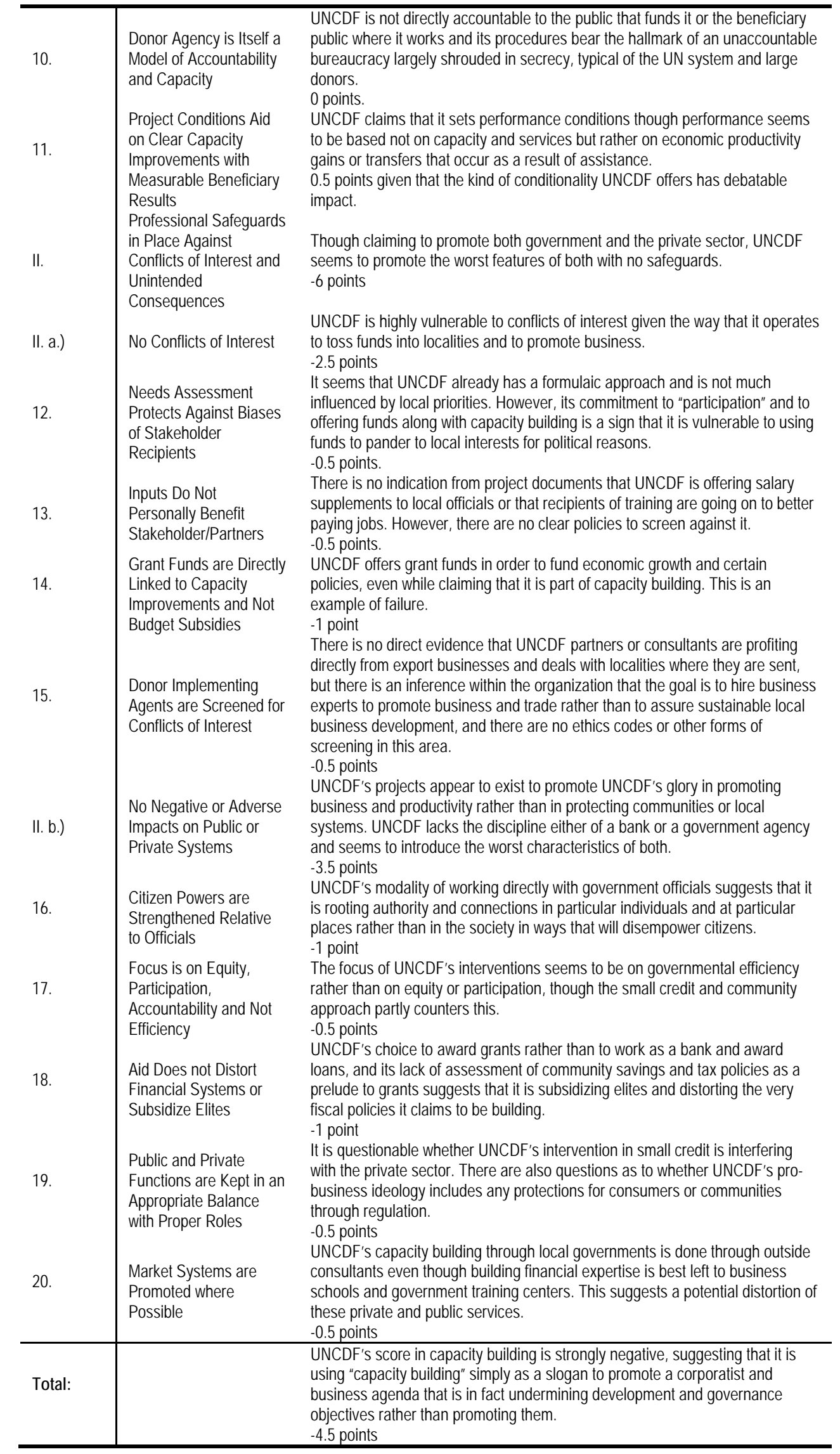


Analysis of UNCDF is based not only on its own statements on its website but also from review of some 8 project documents in as many countries (a 20 percent sample of 40 project countries in 2009) including its logframes, problem statements, results measures, inputs and overall goals and project logic at the request of one of UNCDF's regional offices. A copy of this review of tensions in UNCDF's overall mission and overall deficiencies in standards, is on file with the author. Neither this review nor any similar critique has been posted on UNCDF's website and provides evidence of the organization's inability to follow such claimed procedures of transparency and stakeholder participation in its own activities. 